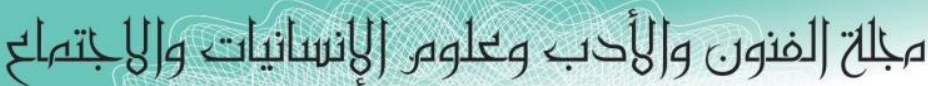

Journal of Arts, Literature, Humanities and Social Sciences

ISSN online: 2414 - 3383

ISSN print: 2616 - 3810

2019 ديسمبر

Volume (46)
العدد (46)

December 2019

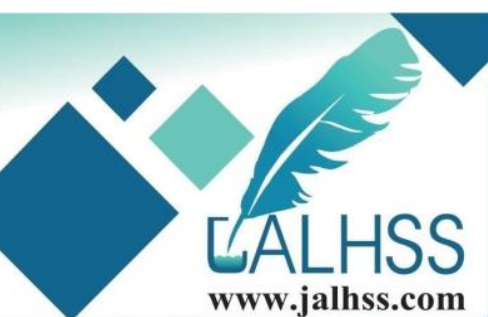

www.jalhss.com

\title{
أهمية إدارة الوقت
}

(دراسة ميدانية من وجهة نظر طلبة كلية التربية للعلوم الإنسانية في ضوء بعض المتغيرات)

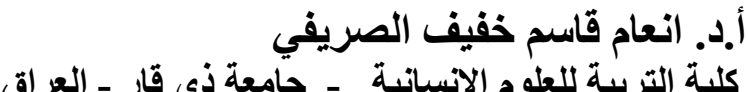 \\ E:234111en@gmail.com
}

يعد الوقت احدى النعم التي أنعمها الله على الإنسان، حيث أن الإنسان يعيش ضمن بعدين أساسيين هما الزمان

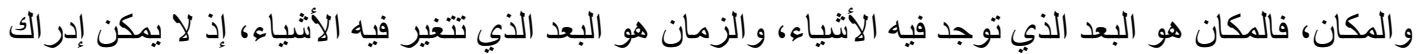

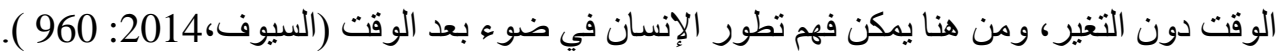

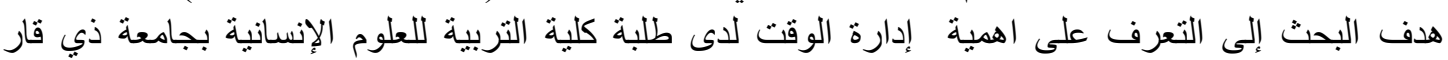

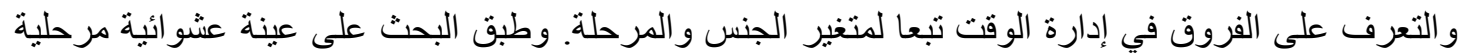

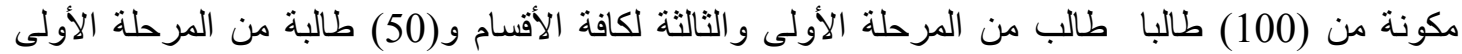

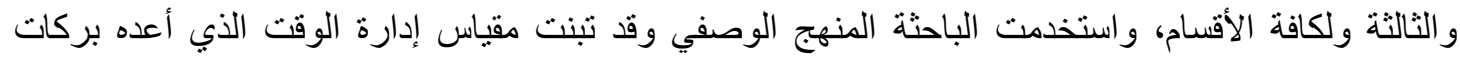

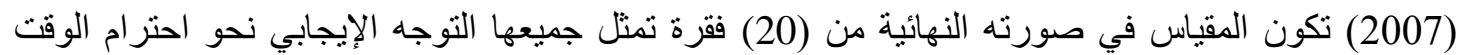

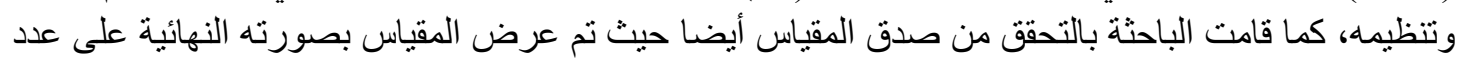
من الخبراء المتخصصين في مجال العلوم التربوية والنفسية وعددهم (8 ) لتقدير مدى تمثل التفية المقياس للصفية

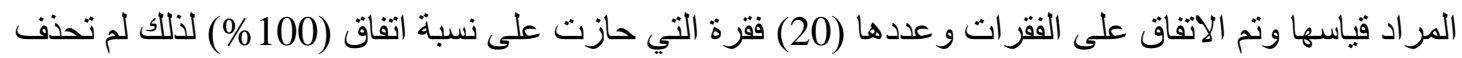

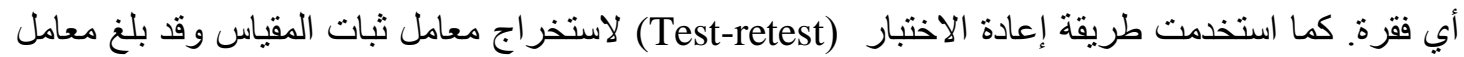

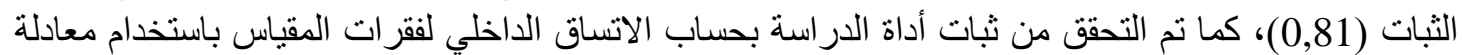

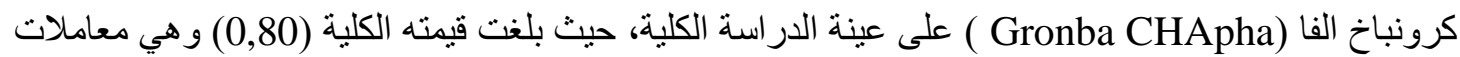

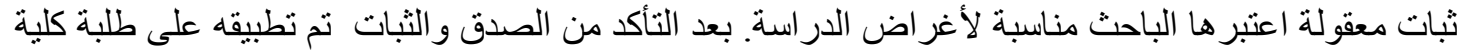

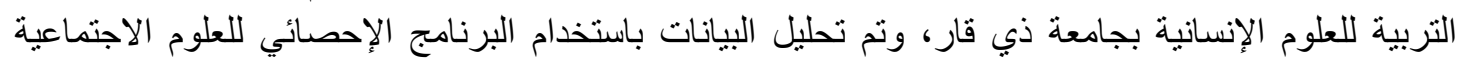
حيث تم استخدام الاختبار التائي (ت) لعينة واحدة ولعينتين مستقلتين، وتوصل البحث الإنى اللى النتائج

$$
\text { (1) تمتع أفر اد عينة البحث بإدارة جيدة للوقت. }
$$

(2) يوجد فرق ذات دلالة إحصائية عند مستوى دلالة(0,05) لدى طلبة كلية التربية للعلوم الإنسانية وفق متغير الجنس لصالح الإناث. (3) لا يوجد فرق ذات دلالة إحصائية عند مستوى دلالة(0,05) لدى طلبة كلية التربية للعلوم الإنسانية وفق

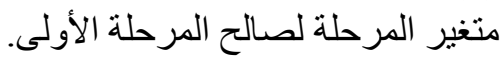
وخرج البحث بمجمو عة من التوصيات و المقترحات. 


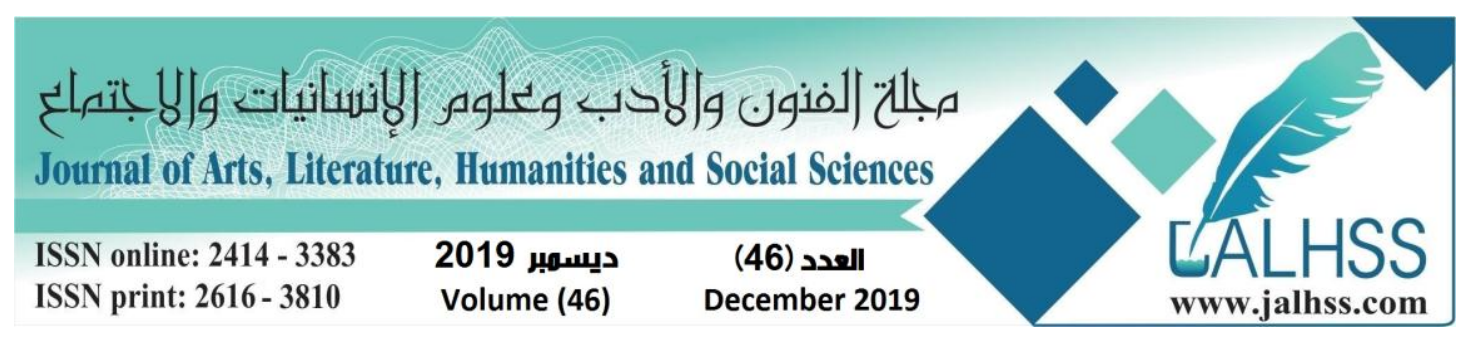

\title{
The Importance of Time Management
}

(A field study from the point of view of students of the Faculty of Education for Humanities in the light of some variables)

\begin{abstract}
Time is one of the blessings that God has granted to man, since man lives within two basic dimensions: time and space. Place is the dimension in which things exist, and time is the dimension in which things change. Time cannot be understood without change. In light after the time (swords, 2014: 960)

The aim of the research was to identify the importance of time management among the students of the Faculty of Education for Human Sciences at the University of Thi Qar and to identify the differences in time management according to the gender variable and the stage. The research was conducted on a random sample of 100 students from the first and third stages of all departments, (2007) This measure is in the final form of $((20)$ all represent a positive trend towards respect for time and organization, and the researcher to verify the veracity of the measure Eza Where it was The final scale of the scale was agreed upon by a number of experts in the field of educational and psychological sciences, (8) to estimate the extent of the measure of the measure to be measured, and the paragraphs were agreed upon (20 paragraphs), which received a percentage of agreement $(100 \%)$. The test method was used to calculate the consistency coefficient of the measurement scales using the Gronba CHApha equation on the total study sample. The total value $(0.80)$ is reasonable stability coefficients considered by the researcher suitable for the purpose of study Yes. After the confirmation of honesty and consistency was applied to students of the Faculty of Education for Human Sciences at the University of Thi Qar, and the data was analyzed using the Social Sciences Statistical Program (SBSS) where the T test was used for one sample and two independent samples, and the research reached the

:following results

1-.The members of the research sample enjoy good time management .

2 - There is a difference of statistical significance at the level of significance $(0,05)$ among the students of the Faculty of Education for human sciences according to .gender variable for the benefit of females

3 - There is no significant difference at the level of significance (0.05) in the (4) students of the Faculty of Education for human sciences according to the variable .phase for the first stage

The research came out with a set of recommendations and proposals.
\end{abstract}


مبلحت (لفنون والأدب وعلوه الإنسانيات والبانتهاع Journal of Arts, Literature, Humanities and Social Sciences

ISSN online: 2414 - 3383

ISSN print: 2616 - 3810
ديسمبر 2019 Volume (46)
العدد (46)

December 2019
¿ALHSS

WWw.jalhss.com

الفصل الاول

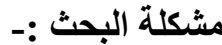

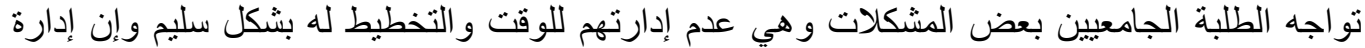

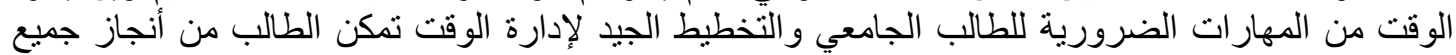

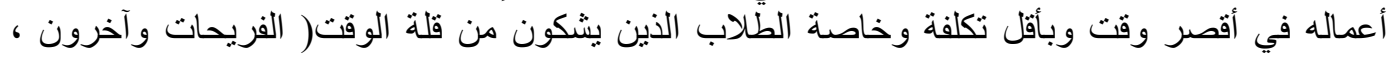

يختلف الطلاب في نظرتهم إلى الوقت تبعاً لتعليمهم ودرجة ثقافتهم و أهدافهم المستقبلية ويمكن تقسيمهر

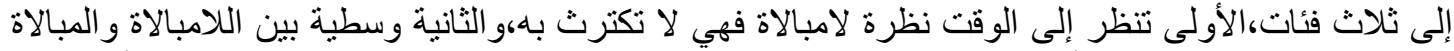

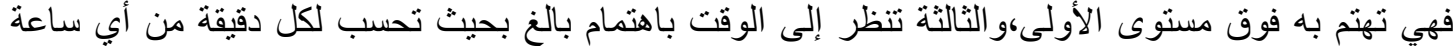

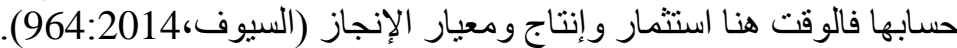

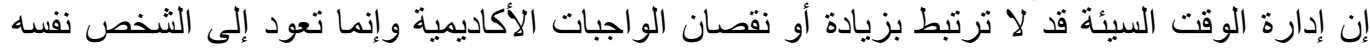

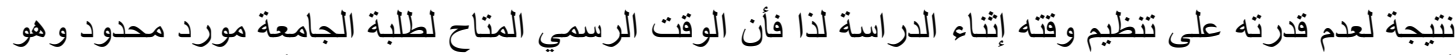

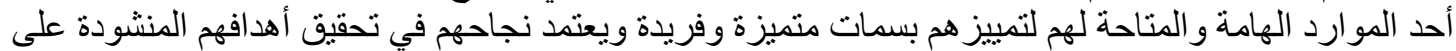

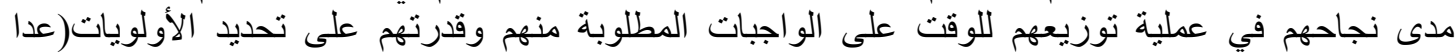

ربة، (3:2006).

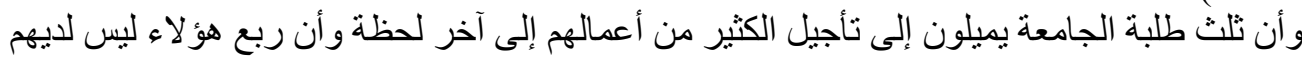

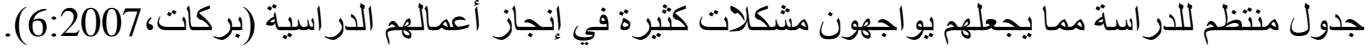

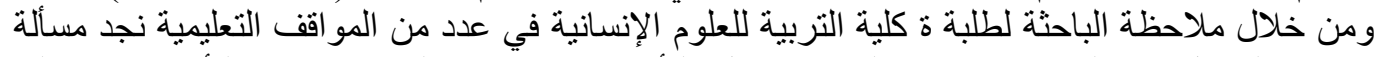

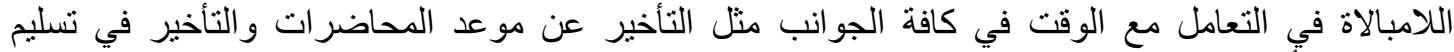

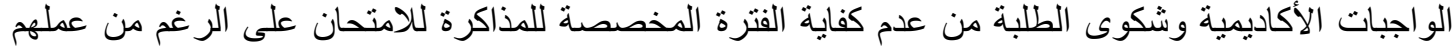

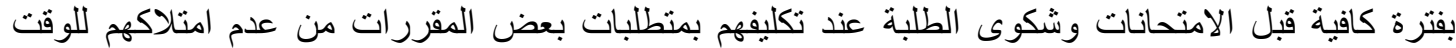

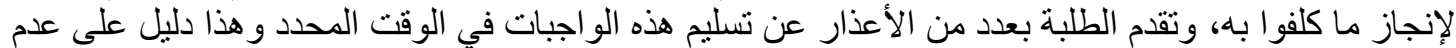

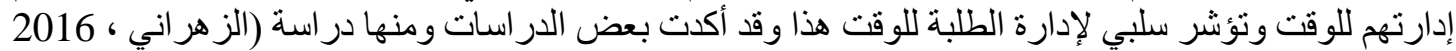

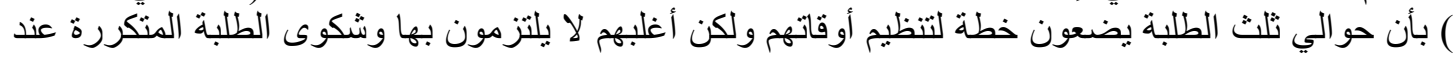

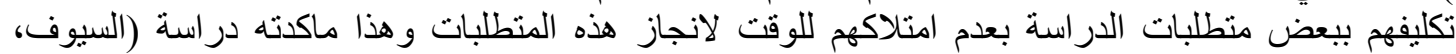

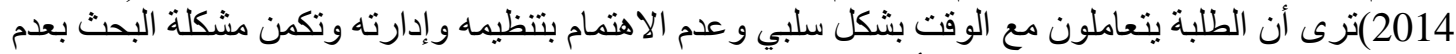

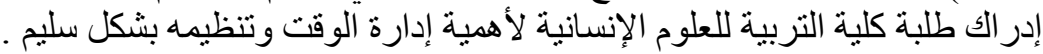

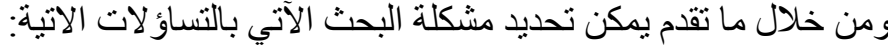

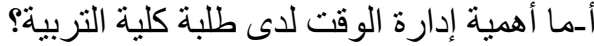

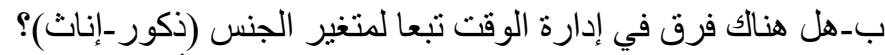
ج-هل هناك فرق في إدارة الوقت تبعا لمتغير المرحلة (أولى - ثالثة)؟

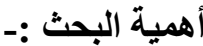

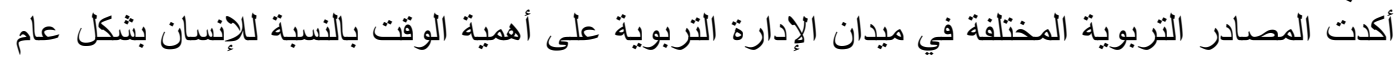

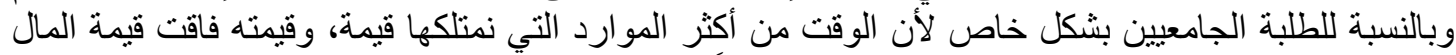

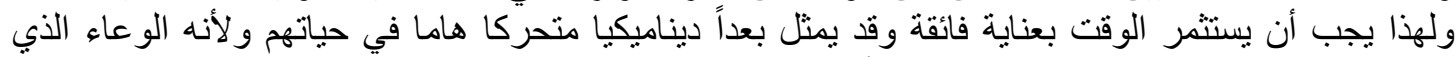

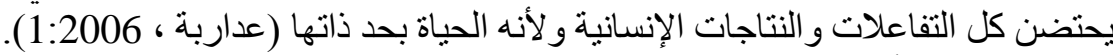

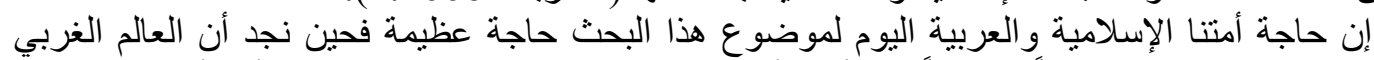

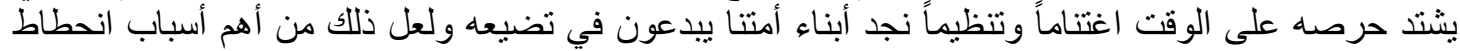

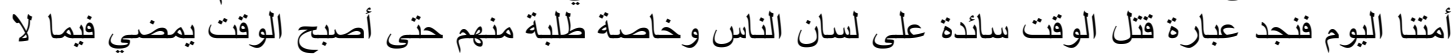

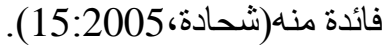

إن للوقت أهمية عظيمة فهو رأسمال الإنسان وو عاء كل عمل وقد أقسم الله سبحانه وتعالى به حين قال

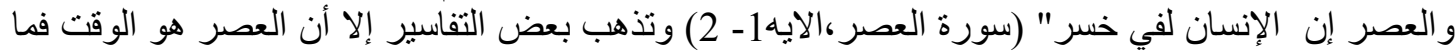




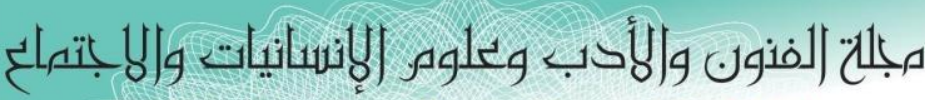

Journal of Arts, Literature, Humanities and Social Sciences

ISSN online: 2414 - 3383

ISSN print: 2616 - 3810

2019 ديسمبر

Volume (46)
العدد (46)

December 2019

\section{¿ALHSS}

WWw.jalhss.com

ينقضي منه لا يمكن تعويضه أو استعادته وهذا من أكبر الدلالات على أهمية وقدره الثمين (الرحيمي ؛ و المارديني ، 227:2014).

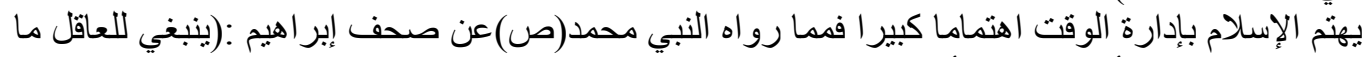

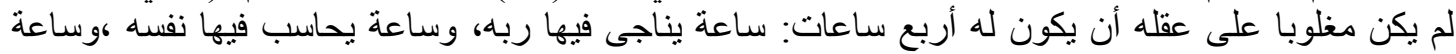

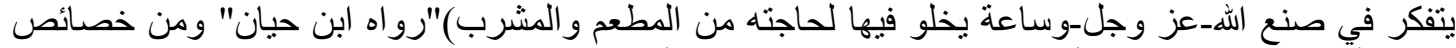

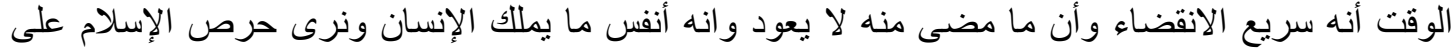

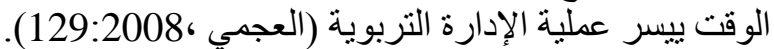

أن ازدياد أهمية الوقت عند الطلبة بصورة الهية عامة دليل عافية الهجتمع ثقافيا وحضاريا كما أن الاستخدام

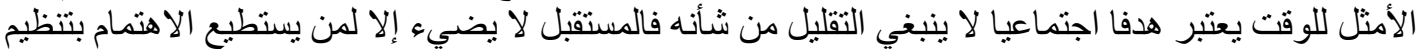

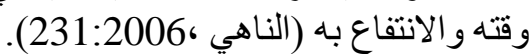
الأهداف و الأن يهدف البحث الحالي إلى ما يأتي:-

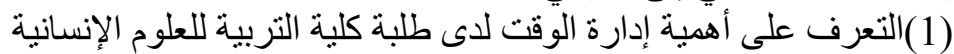

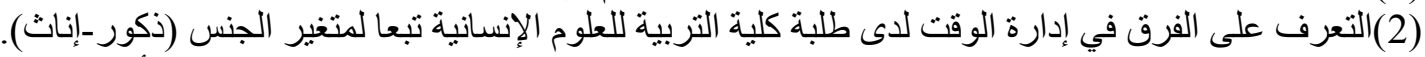
(3) التعرف على الفرق في إدارة الوقت لادى طلبة كلية التربية للعلوم الإنسانية تبعا لمتغير المرحلة (أولى ثالثية).

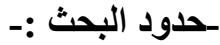

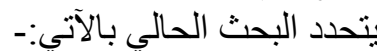

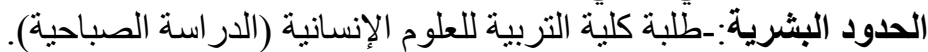

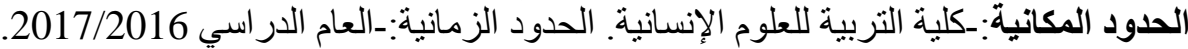
تحديد المصطلحات:-

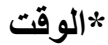

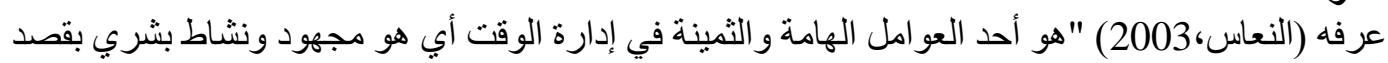

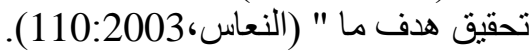

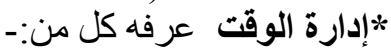

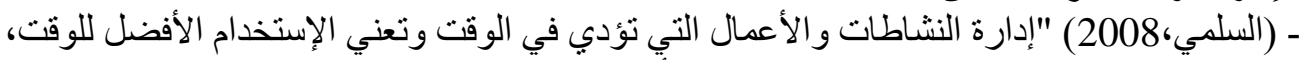

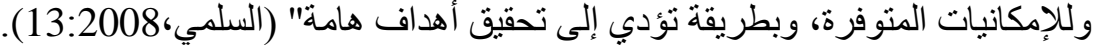

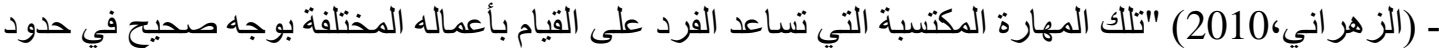

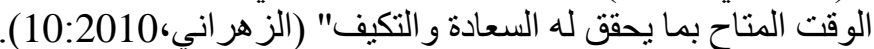

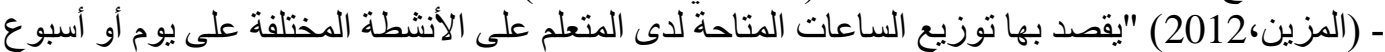

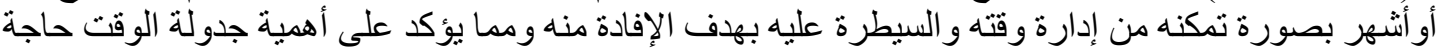

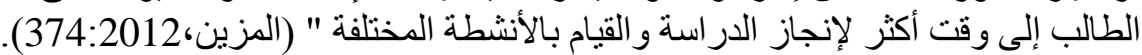

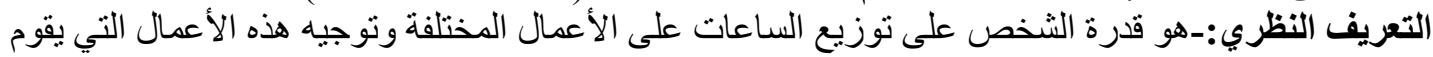

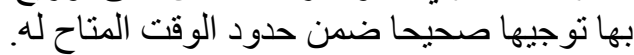

التعريف الإجرائي:-هو الدرجة الكلية التي يحصل عليها الطلبة في ضوء إجاباتهم على فقرات مقياس إدارة الوقت المعد في البحث الحمالي.

\section{الفصل الثاني \\ الإطار النظري}

ـ الوقت في القرآن الكريم

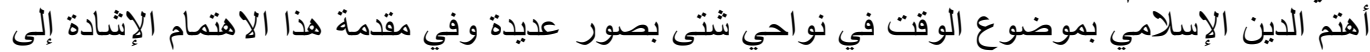

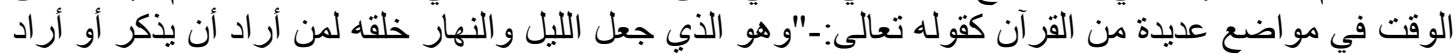

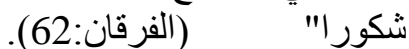
وقوله تعالى:- "ولقد خلقنا السماو ات و الأرض وما بينهما في ستة أيام وما مسنا من لغوب" (ق:38). و أقسم الله 


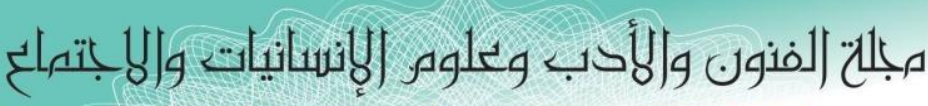

Journal of Arts, Literature, Humanities and Social Sciences

ISSN online: 2414 - 3383

ISSN print: 2616 - 3810

2019 ديسمبر

Volume (46)
العدد (46)

December 2019
LALHSS

WWw.jalhss.com

ببعض المو اقيت كما جاء في محكم التنزيل "و الفجر وليال عشر" (الفجر:1-2). وقوله تعالى: "و الليل إذا يغشى

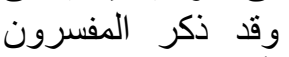

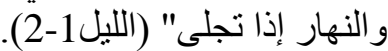

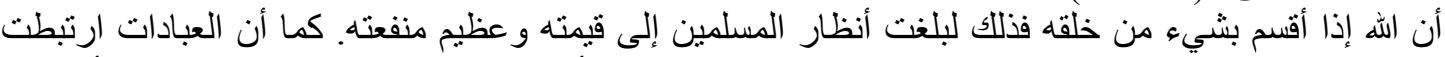

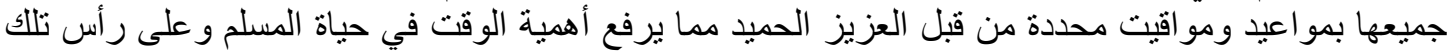

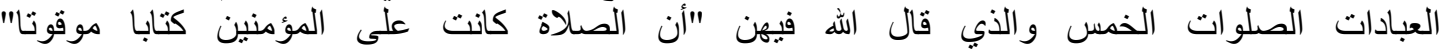
(النساء:103).و الصلاة عبارة تتكرر خمس مرات في اليوم و الليلة.

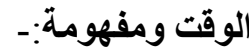

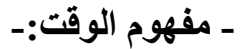

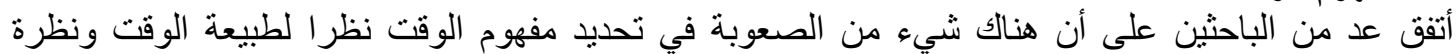

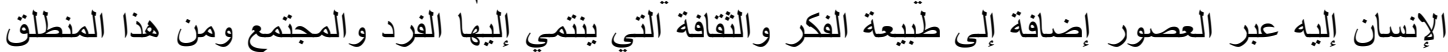

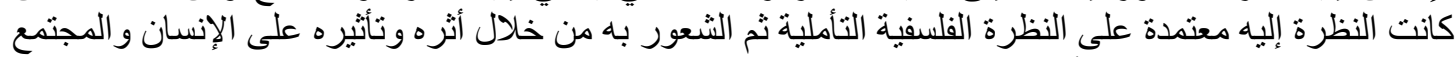

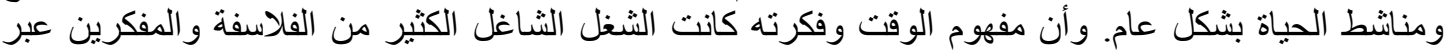

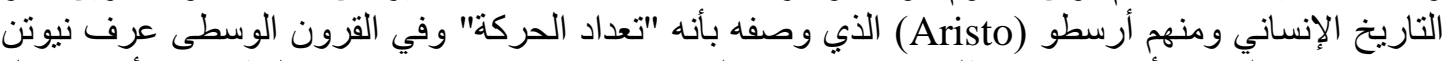

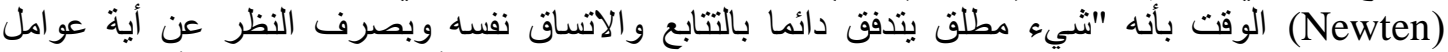

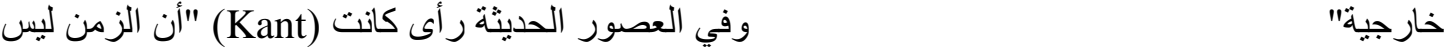

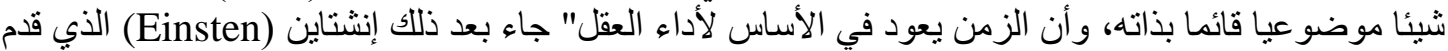

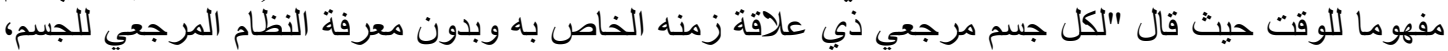

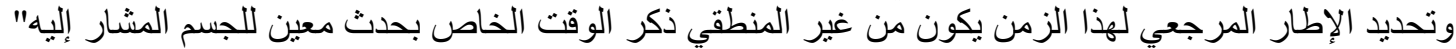

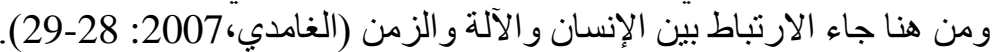

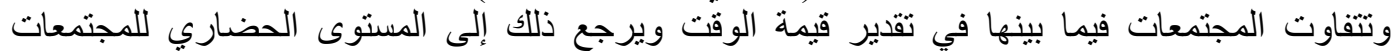

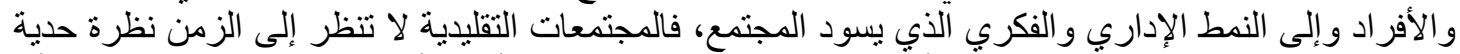

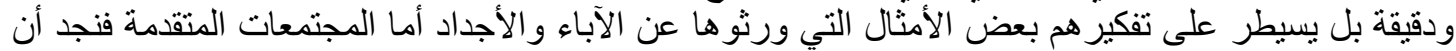

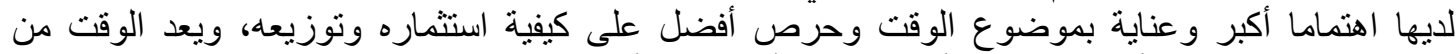

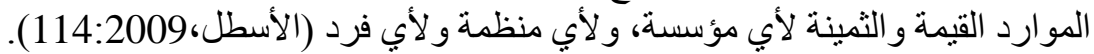

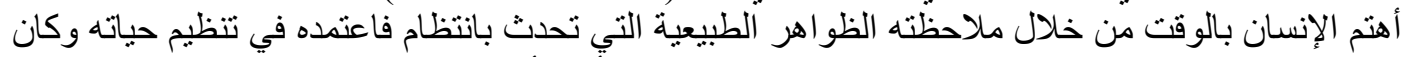

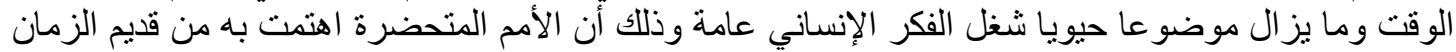

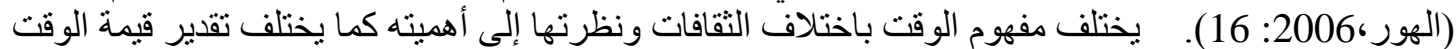

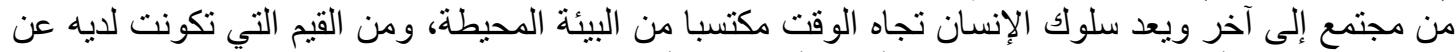

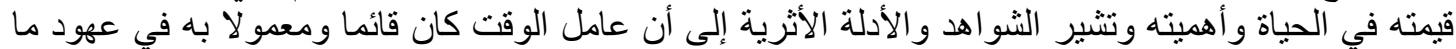

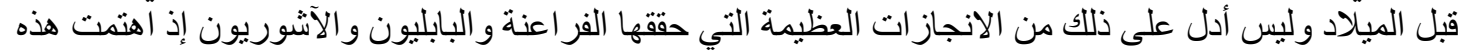

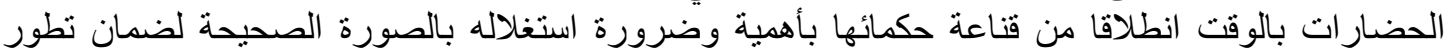

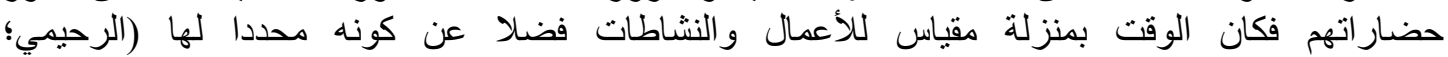

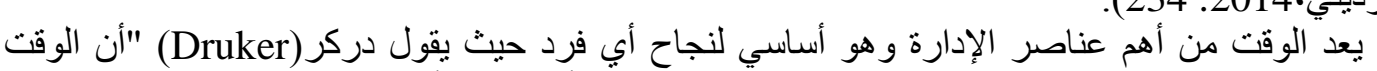

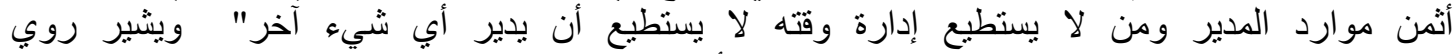

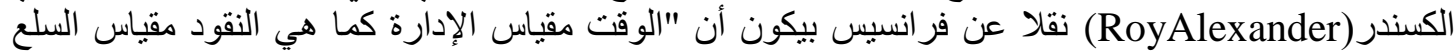

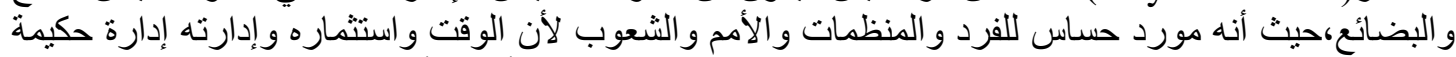

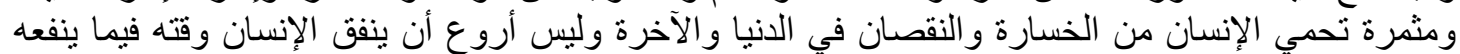

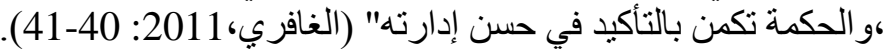
ويقول الحسن البصري في الوقت "يا أبن آدم إنماً أنت أيام معدودة كلما ذهب يوم ذهب بعضك ويوشك إذا ذهب

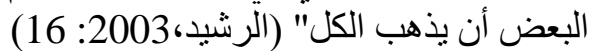
وجاء في القاموس الأمريكي المشهور وابستر (Websters) الذي يقول بأن: "الوقت هو سلسلة منصلة من 


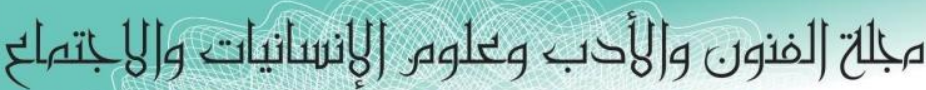

Journal of Arts, Literature, Humanities and Social Sciences

ISSN online: 2414 - 3383

ISSN print: 2616 - 3810

2019 ديسمبر

Volume (46)
(46) (4) (العدد)

December 2019

\section{LALHSS}

Www.jalhss.com

أحداث يتبع أحدها الآخر في الماضي مرورا بالحاضر إلى المستقبل"و هذا التعريف للوقت هو ما أختارهو واعتمده

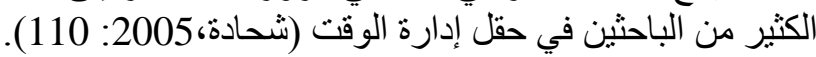

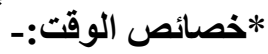

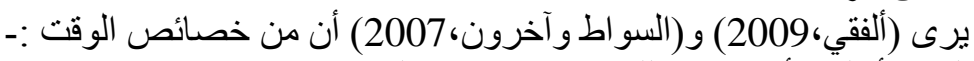

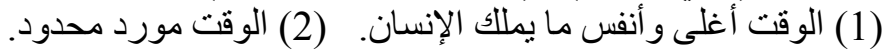

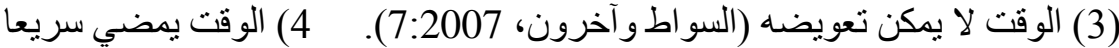

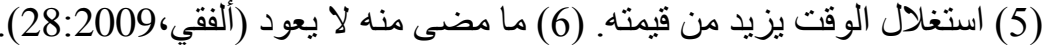

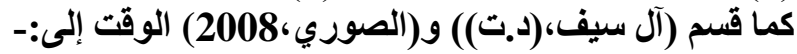

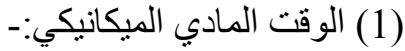

و هو مقياس لحركة جسم مادي بالنسبة لجسم مادي أخر كالفترة التي تستغرقها الأرض في الدوران حول الثمس،

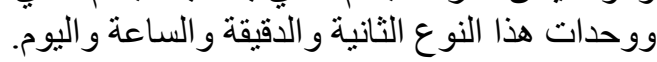

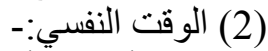

وهو نوع أخرمنيّ أنواع الثعور الداخلي بقيمة أخرى للوقت حيث يؤثر الحدث النفسي في ذلك إذا كان سعيدا أو

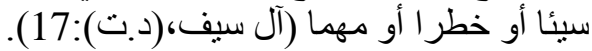

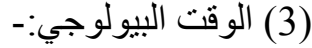

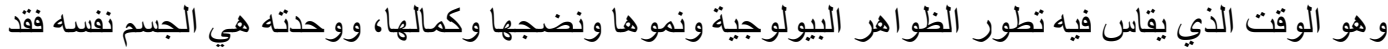

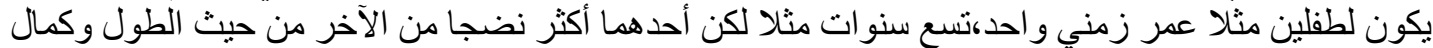

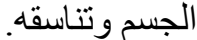

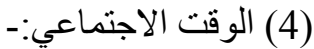

وهو الذي يربط فيه تقدير الوقت بأحداث اجتماعية مهمة إما عملية أو محلية وهذا تختلف فيه المجتمعات ولذا

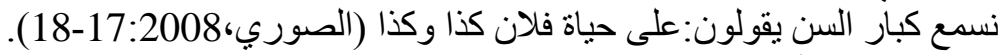

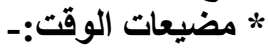

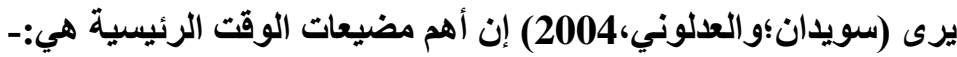

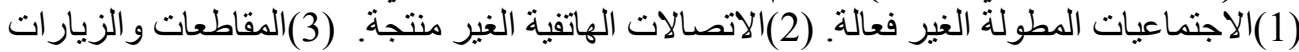

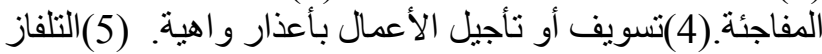
(سويدان؛و العدلوني، (5) (81:2004).

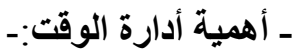

أن الذين ينظرون إلى الوقت بعين الاهتمام هم الذين يحققون انجاز ات كثيرة في حياتهم الثخصية و المهنية،

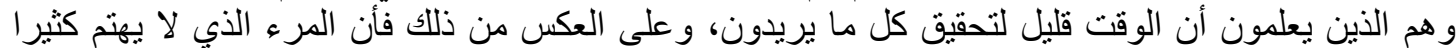

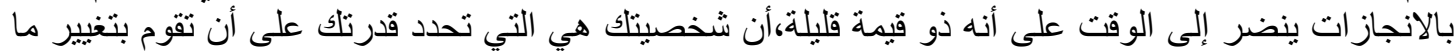

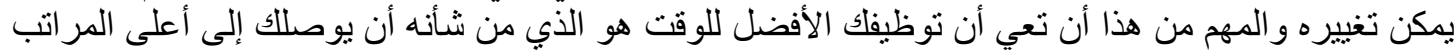

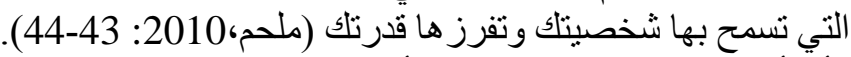
و أن أساس نجاح الفرد في بيئة الأعمال الحالية يكمن في مدى إدر اكه لأهمية الوقت كثروة أساسية وجب عليه

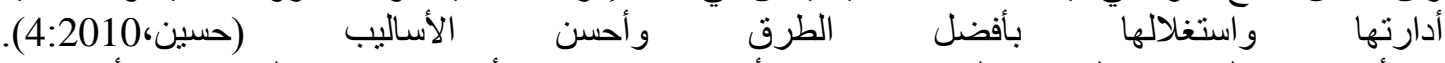

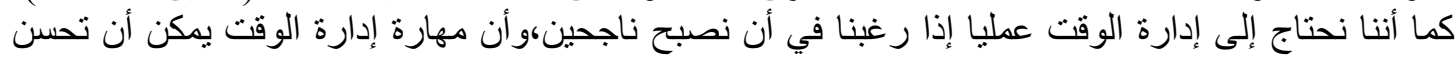

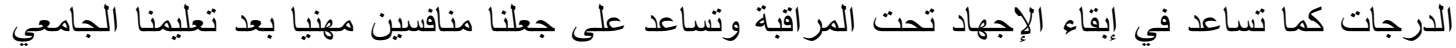

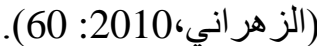

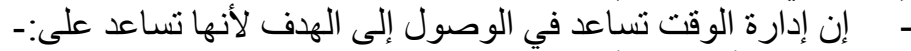

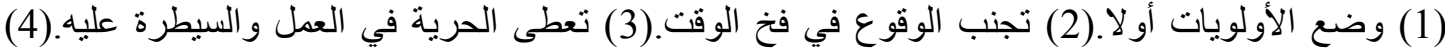

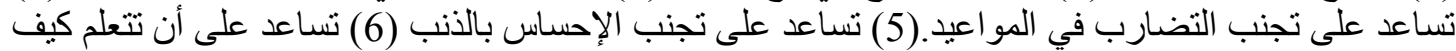
تخطط بذكاء أكبر، لا بجهة أكبر في (ملحم،2010: 49)

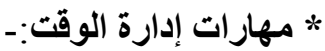

يرى (العياصرة، ئ، 2013) أن مهارة إدارة الوقت هي:- 


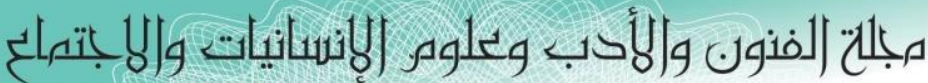

Journal of Arts, Literature, Humanities and Social Sciences

$\begin{array}{llc}\text { ISSN online: } 2414-3383 & \text { (46) } \\ \text { ISSN print: } 2616-3810 & \text { Volume (46) } & \begin{array}{c}\text { (46) } \\ \text { December } 2019\end{array}\end{array}$

المهارة التي تنتخدم من أجل الحصول أفضل استغلال للوقت المرتبط بواجبات أو مهام أو أعمال محددة

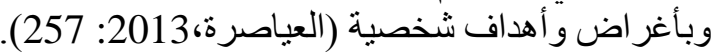

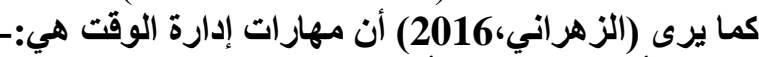

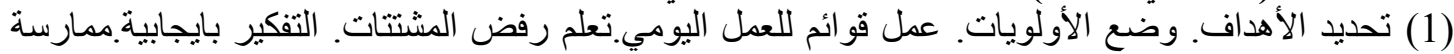

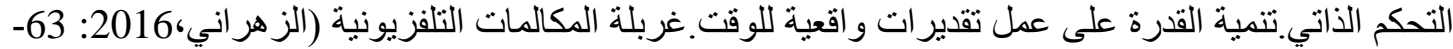

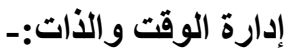

يختلف مفهوم إدارة الوقت لأى الأفر اد باختلاف دو افعهر واحتياجاتهم وطبيعة وظائفهمكما يختلف أيضا

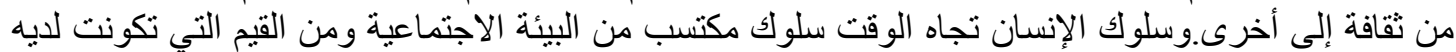

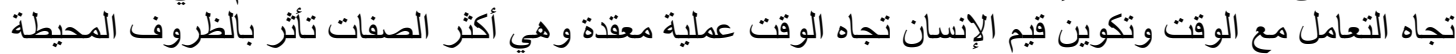

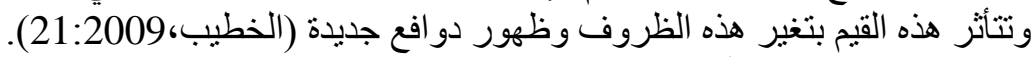

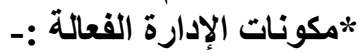
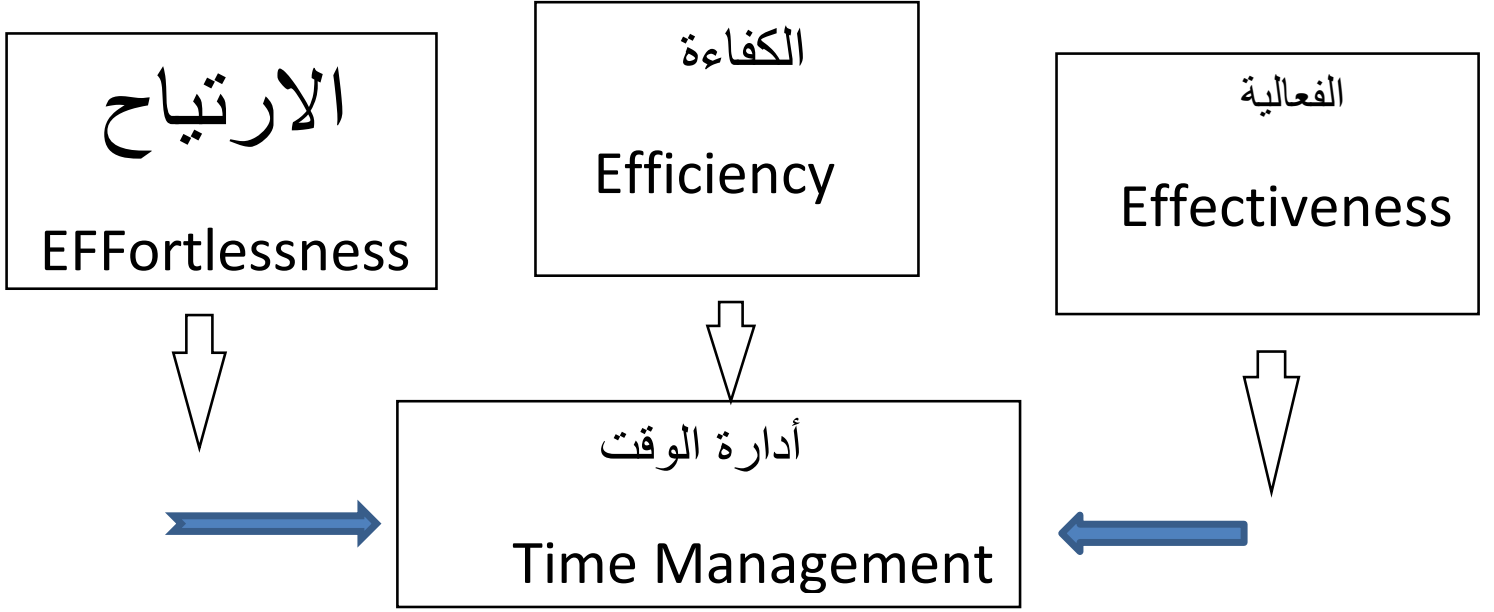

شكل (1) مكونات الإدارة الفعالة للوقت

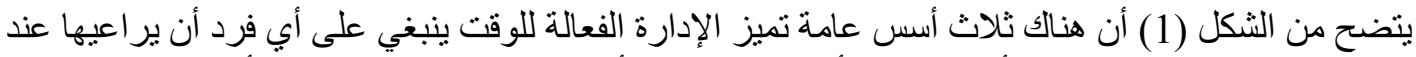

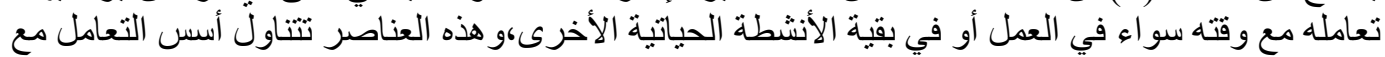

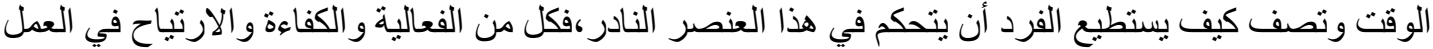

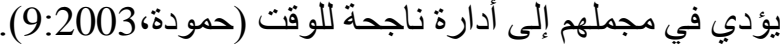

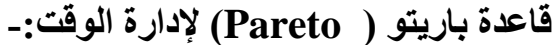

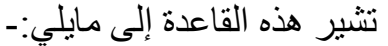

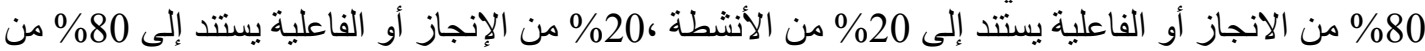

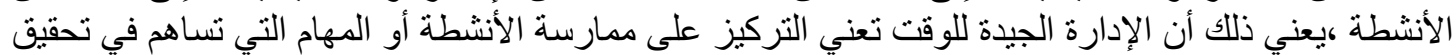

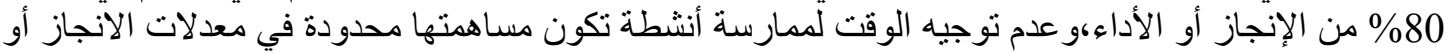

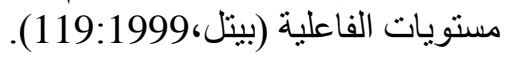


مجلحت (لفنون والأدب وعلوه الإنسانيات والبانتهاع Journal of Arts, Literature, Humanities and Social Sciences

ISSN online: 2414 - 3383

ISSN print: 2616 - 3810

2019 ديسمبر Volume (46)
(46) العدد

December 2019

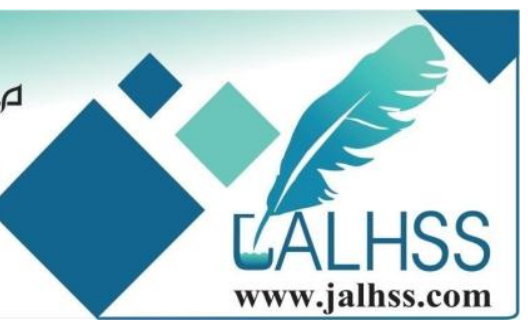

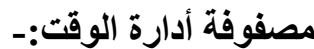

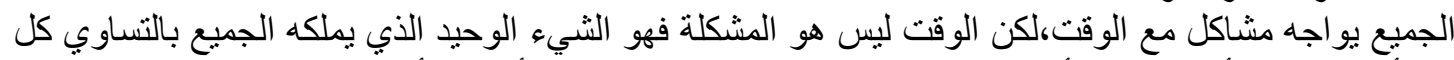

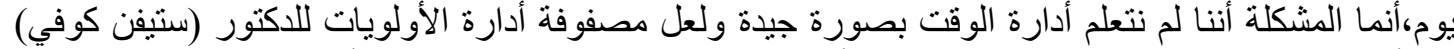

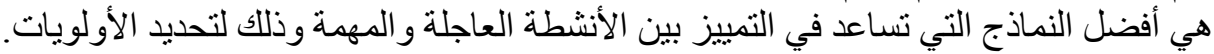

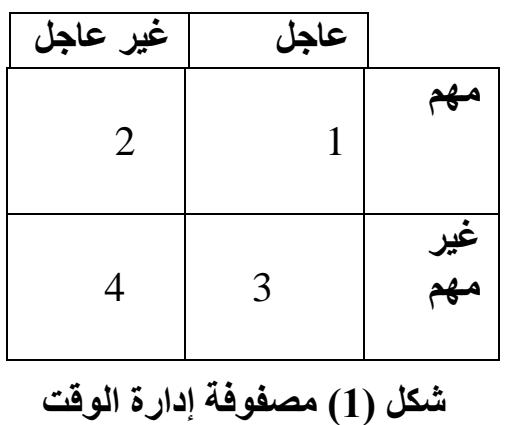

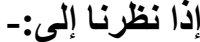

المربع الأول من المصفوفة: و الطو ارئ و المفاجئات نجد أن الأنشطة هنا مهمة و عاجلة و عليك أن تؤديها بنفسك

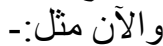

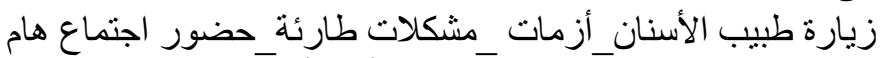

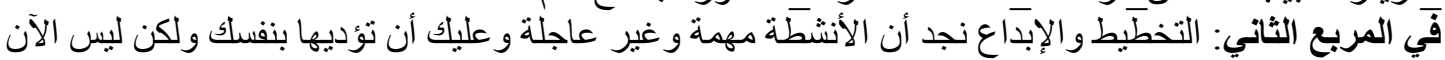

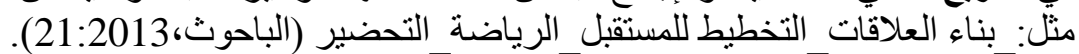

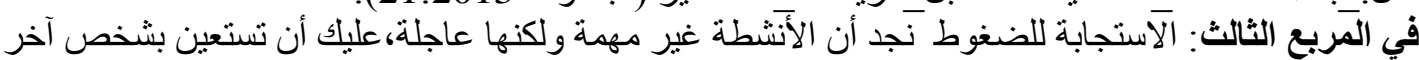

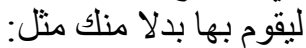
بعض الاجتماعات الغير ضرورية زيار الات بات الأصدقاء المفاجئة مكالمات هاتفية

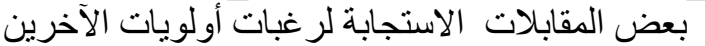

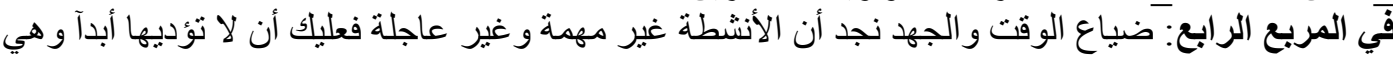

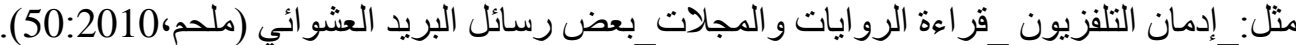
* خطوات إدارة الوقت آلناجحة:هناك ست خطو ات عملية لإدارة الوقة الوقات الناجحة وهي مجسدة بشكل واضح في المخطط المفصل أدناه

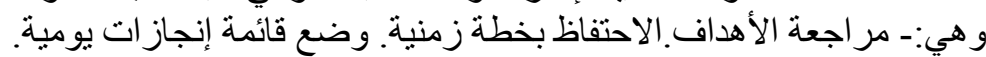

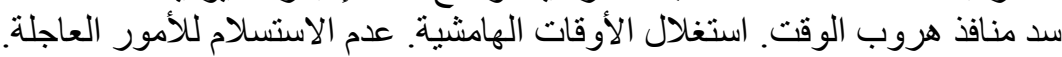



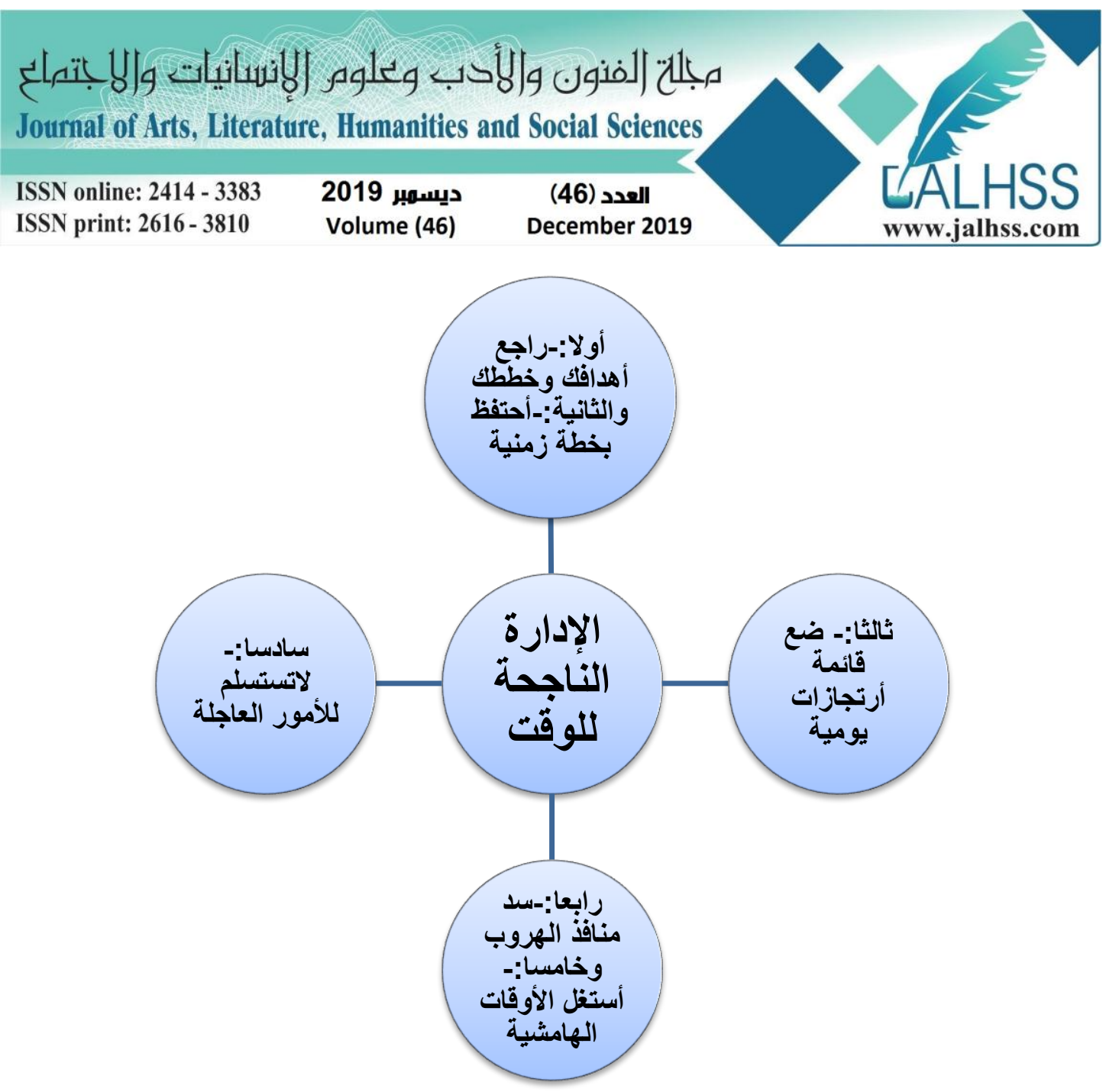

شكل (2) مخطط مفاهيمي لإدارة الوقت الناجحة (عداربة،2006: 25-24).

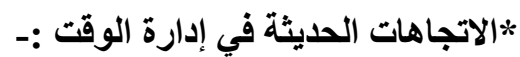

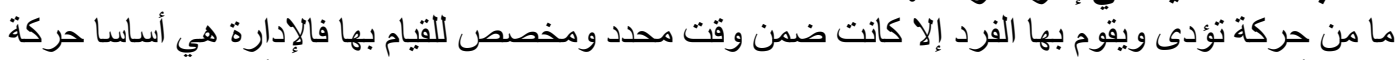

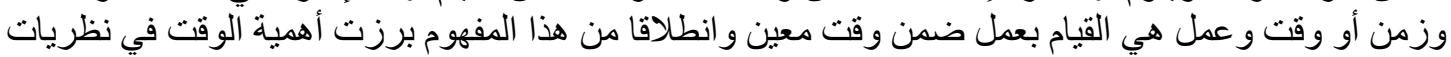

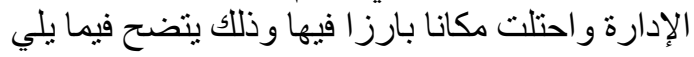

أولا :- نظرية الإدارة العلمية:-

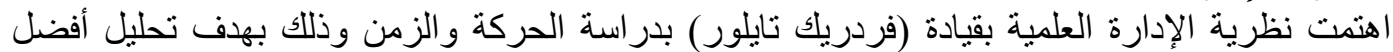

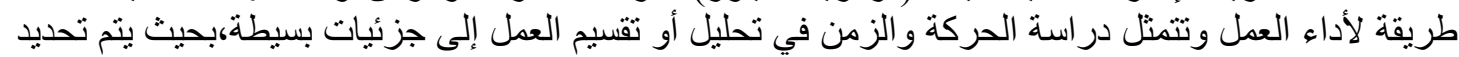

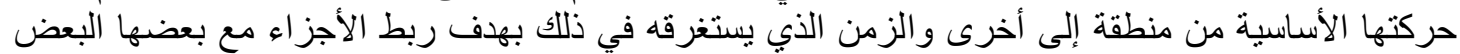

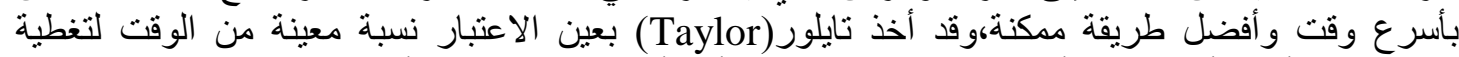

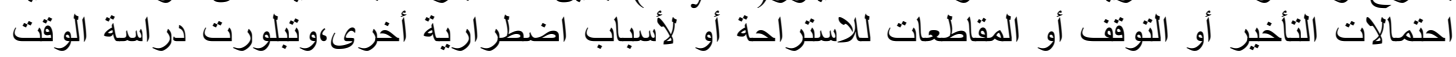

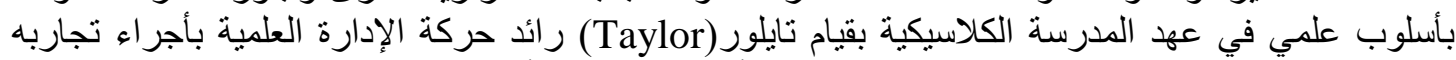
على الحركة والوقت في إحدى الثركات الصناعية الأمريكية ولاحظ أن هناك ضياكياعا كبيرا في الإنتاج نتيجة

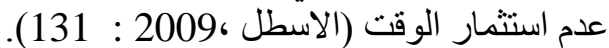

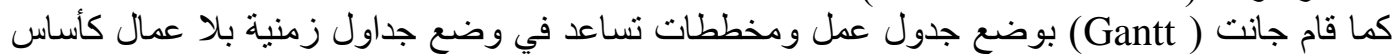

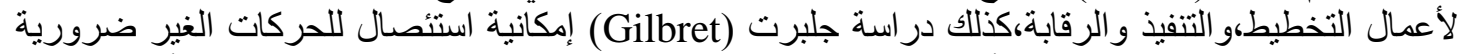

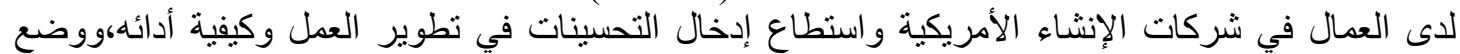

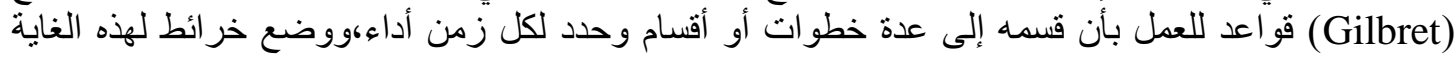


مبلحت (لفنون والأدب وعلوه الإنسانيات والبانتهاع

Journal of Arts, Literature, Humanities and Social Sciences

ISSN online: 2414 - 3383

2019 ديسمبر

ISSN print: 2616 - 3810

Volume (46)

العدد (46)

December 2019

أطلق عليها (خرائط التدفق Flowchart) فهذه الخرائط نساعد على دراسة أية عملية بتفاصيلها

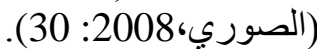
ت تانيا:- المدرسة السلوكية:-

اعتمدت المدرسة السلوكية على نظرية العلاقات الإنسانية تركزت الإنهات على بناء المؤسسة من الوجهة

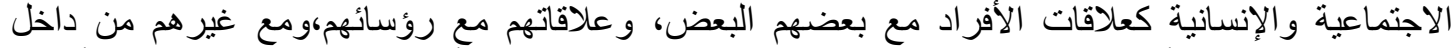

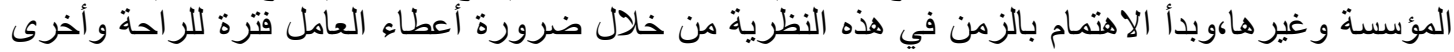

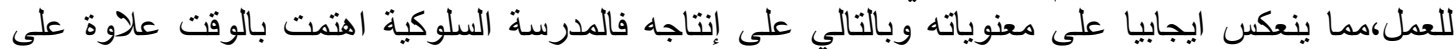

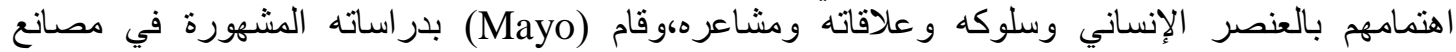

(Studies Hawthormhe)

وتوصل إلى أن ظاهرة تقيس العمال و عدم الانتظام في أوقات الدوام يقلل من الإنتاج (عايش،2009: 114).

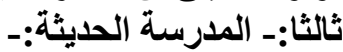

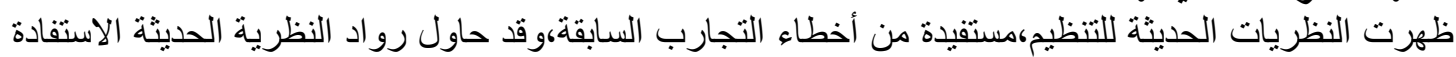
من أفكار الباحثين،ومن أهم الهم هذه النظريات ما يلي:-

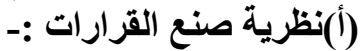

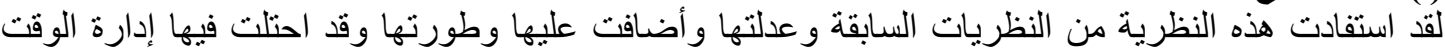

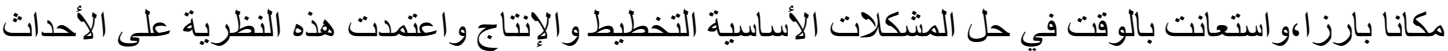

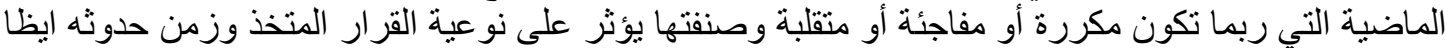

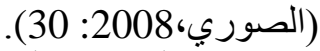

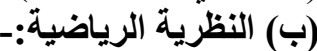

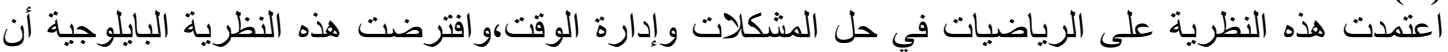

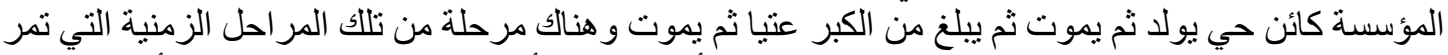

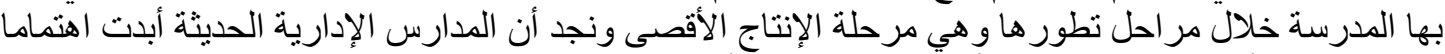

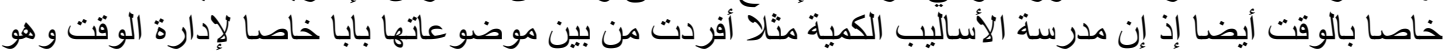

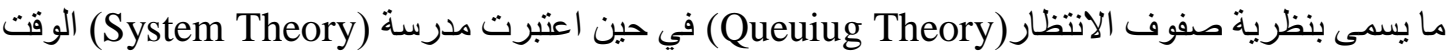
كأحد متغيرات البيئة الخارجية التي لاتسنطيع السيطرة عليها لأنه متحرك ويسير إلى الأمام بشكل منتظم

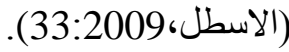

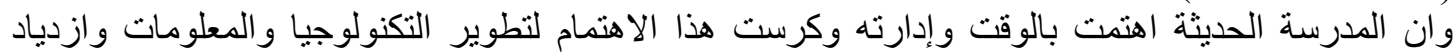

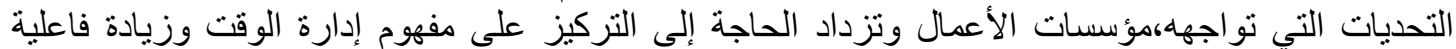
استثمار ها ورفع مستو يات الأداء لافع عملية التنمية وتحقيق مستويات أفضل من لرفاه الأل الاقتصادي والاجتماعي

(الصوري، (30:2008).

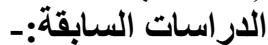

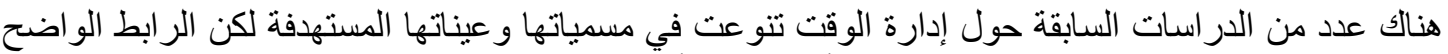

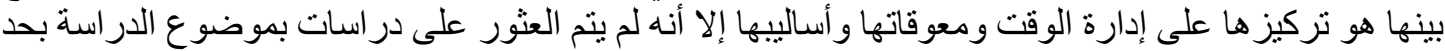

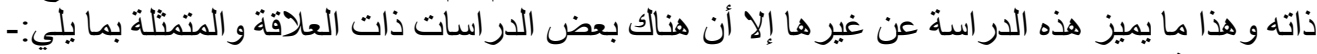

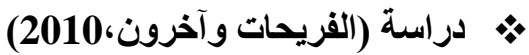

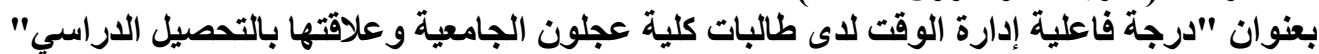

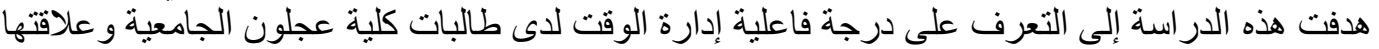

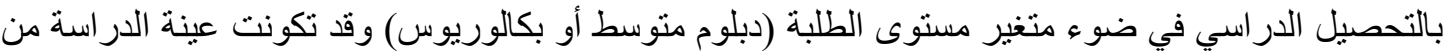

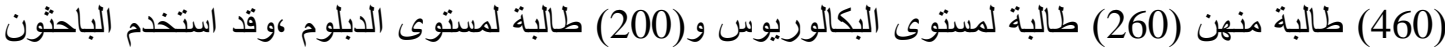

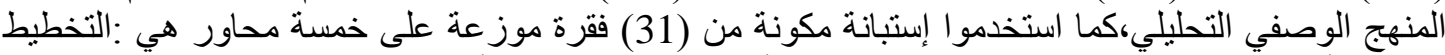

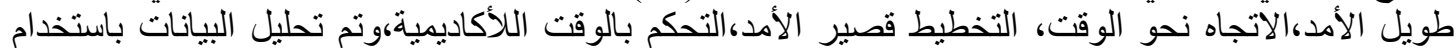

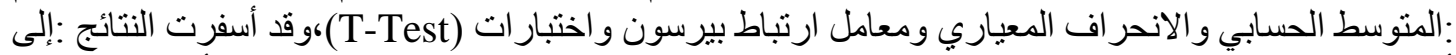

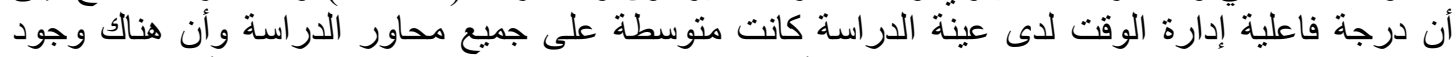

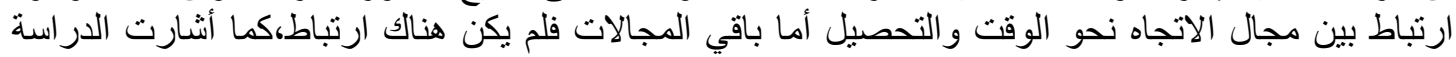




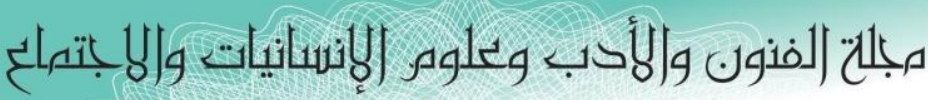

Journal of Arts, Literature, Humanities and Social Sciences

\begin{tabular}{|c|c|c|}
\hline & ديسهبر 2019 & العدد (46) \\
\hline
\end{tabular}

وجود فروق ذات دلالة إحصائية عند مستوى الدلالة ( 55 > 0,05) لمرحلة البكالوريوس و الدبلوم لصالح الدبلوم

في مجال التخطيط قصير الأمد،أما باقي المجالات فلا توجد دلالة إحصائية(الفريحات وآخرون،

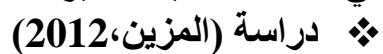
بعنوان "فاعلية إدارة الوقت لاى طلبة الجامعة الإسلامية وعلاقتها بالتحصيل الدراسي في ضوء بعض

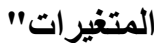

هدفت هذه الدراسة إلى التوصل لمعرفة دور الجامعة في زيادة فاعلية إدارة الوقت وعلاقتونها بالتحصيل

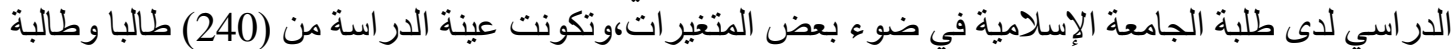

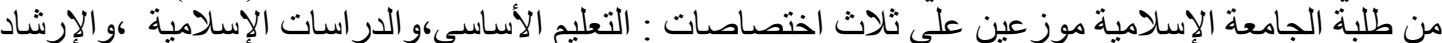

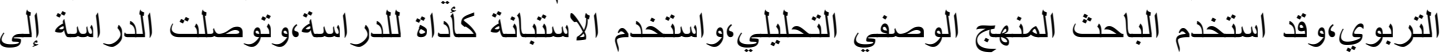

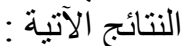

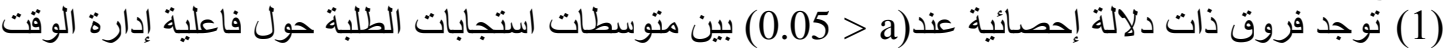

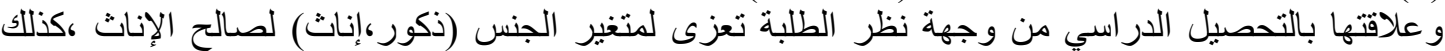

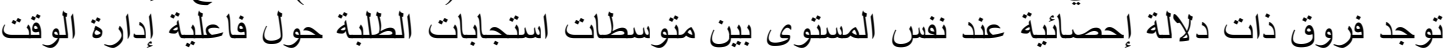

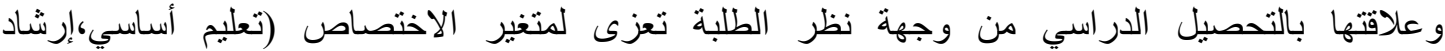
نفسي،ودر اسات إسلامية)لصالح التحالئيم الأساسي.

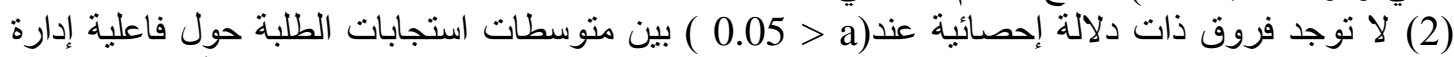

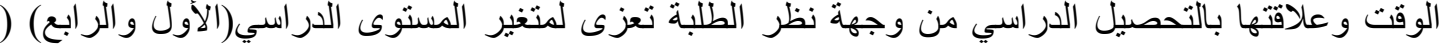

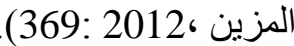

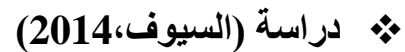

بعنوان "استراتيجيات إدارة الوقت لدى طلبة كلية العلوم التربوية في الجامعة الأردنية"

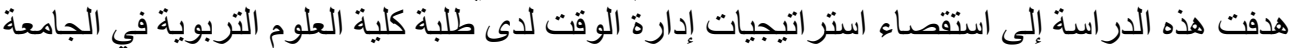

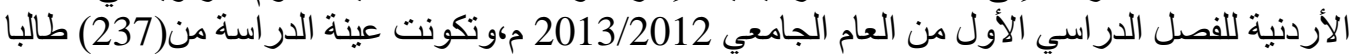

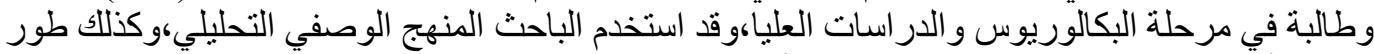

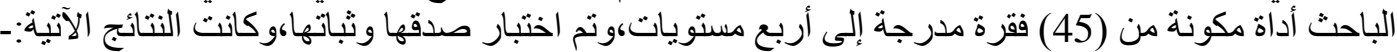

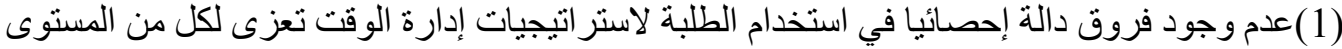

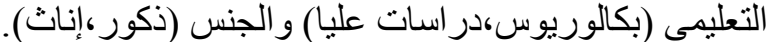
(2)وجود فروق دالة إحصائيا في استخدام الطلبة لاستر اتيجيات إدارة الوقت تعزى للمعدل المدل التر اكمي ولصالح معدل(جيد جدا،ممتاز) (السيوف، 2014 2019 (9).

\section{الفصل الثالث \\ منهجية البحث وإجراء(ته الته}

"منهج البحث:استخدمت الباحثة|لمنهج الوصفي ويعرفه (ملحم،2000) بأنه "أحد أثنكال التحليل و التفسير العلمي المنظم

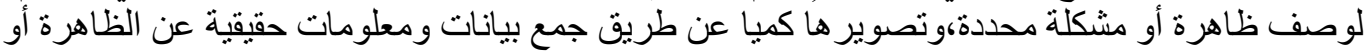

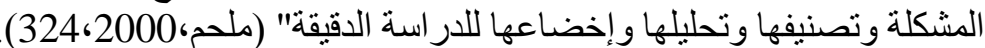

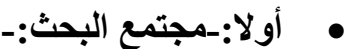

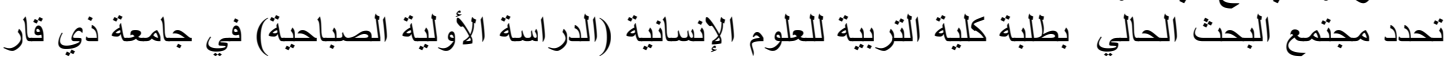

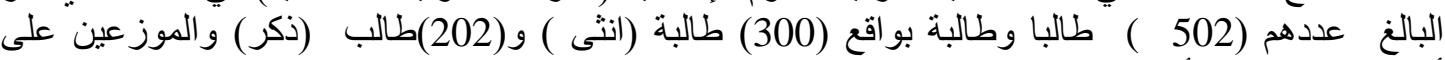
أقسامها البالغة (5) أقسام للعام الدراسي (2017-2016). 
مبلحت (لفنون والأدب وعلوه الإنسانيات والبغتهماع Journal of Arts, Literature, Humanities and Social Sciences

ISSN online: 2414 - 3383

ISSN print: 2616 - 3810

2019 ديسمبر

Volume (46)
(46) العدد

December 2019
LALHSS

WWw.jalhss.com

شملت عينة البحث (100)طالب وطالبة من كافة الأقسام التي تمثل كلية التربية للعلوم الإنساني/جامعة ذبي

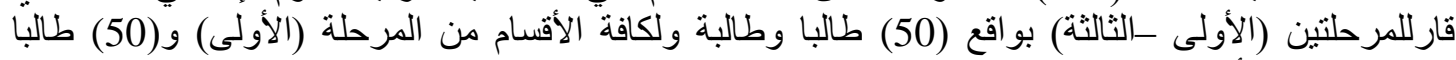

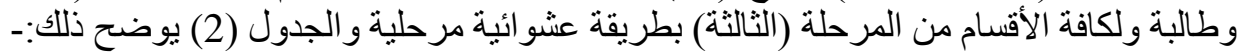

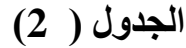

توزيع افراد مجتمع وعينة البحث حسب الكلية والقسم والجنس (

\begin{tabular}{|c|c|c|c|c|c|c|}
\hline \multirow[t]{3}{*}{ المجمو ع } & \multirow{2}{*}{\multicolumn{2}{|c|}{ المرحلة }} & \multicolumn{2}{|c|}{ المرحلة } & القسم & \multirow{3}{*}{ التلية } \\
\hline & & & & & & \\
\hline & $\dot{H}$ & $\dot{j}$ & $\dot{H}$ & $\dot{j}$ & الجنس & \\
\hline 20 & 5 & 5 & 5 & 5 & الجغرافية & للعطوم \\
\hline 20 & 5 & 5 & 5 & 5 & اللغة الانكليزية & الانسانية \\
\hline 20 & 5 & 5 & 5 & 5 & علم النفس & \\
\hline 20 & 5 & 5 & 5 & 5 & التاريخ & \\
\hline 20 & 5 & 5 & 5 & 5 & اللغة العربية & \\
\hline 100 & 25 & 25 & 25 & 25 & & المجموع \\
\hline
\end{tabular}

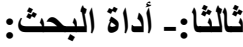

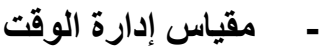

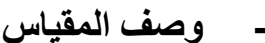

بعد إطلاع الباحثة على عدد من الأدبيات و الدر اسات السابقة والتعريفات العديدة لإدارة الوقت، و المقاييس التي

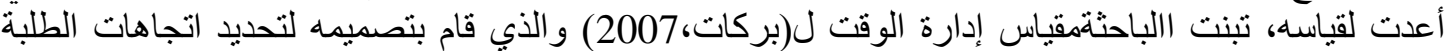

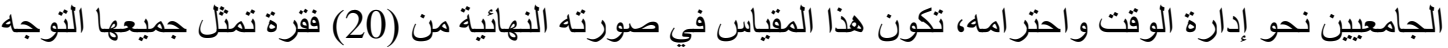

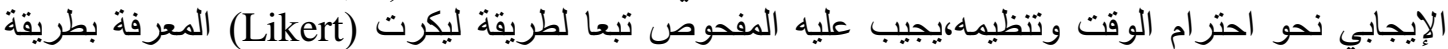

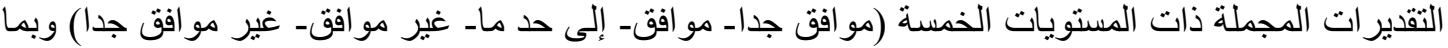

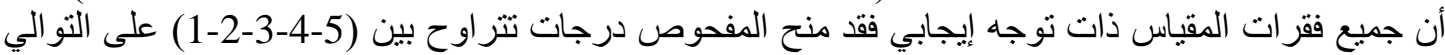

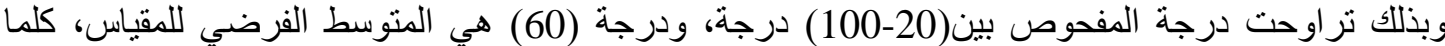

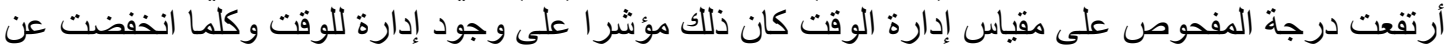

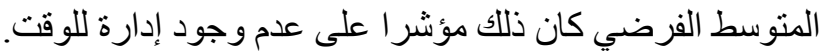

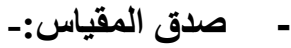
للتحقق من صدق هذا المقياس نم استخدام طريقة صدق المحكمين، حيث وزع المقياس في صورته المبدئية على لمي

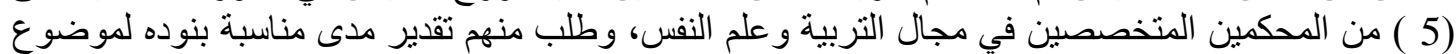

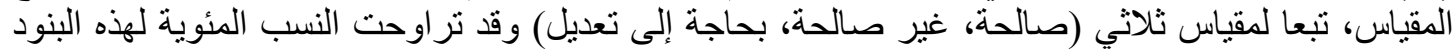

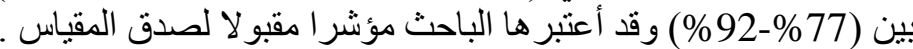

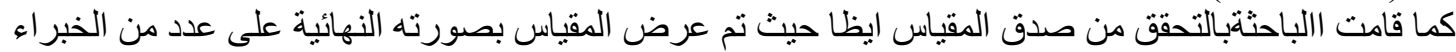

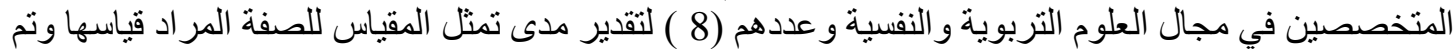

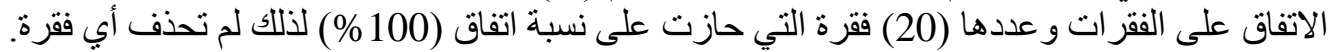

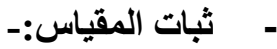
استخدمت طريقة إعادة التطبيق (Test-retest) لاستخر اج معامل ثبات المقياس على عينة استطلاعية تكونت

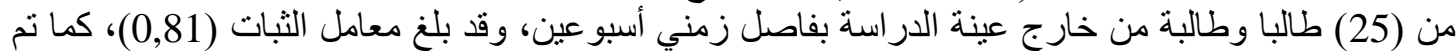

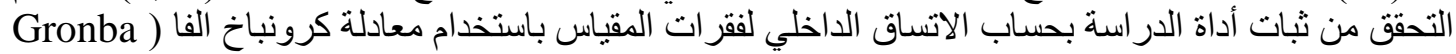
( CHApha الباحث مناسبة لأغر اض الدر استة الإسة

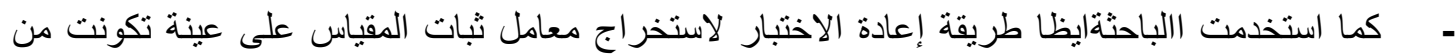
(20) طالبا وطالبة من كلا المرحلتين (الأولى- والثالثة) ومن كافة الثانة أقسام كلية التربية للعلوم الإنسانية بفاصل

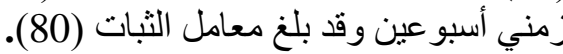




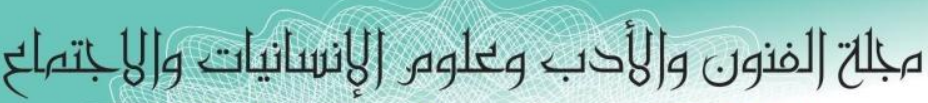

Journal of Arts, Literature, Humanities and Social Sciences

ISSN online: 2414 - 3383

ISSN print: 2616 - 3810

2019 ديسمبر

Volume (46)

العدد (46)

December 2019

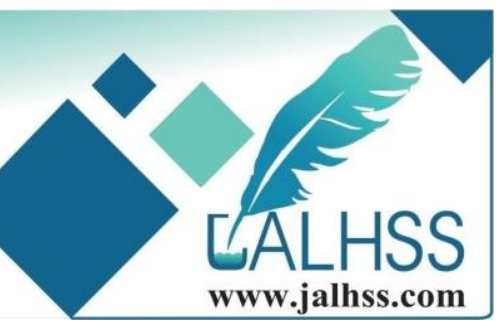

-

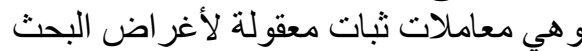

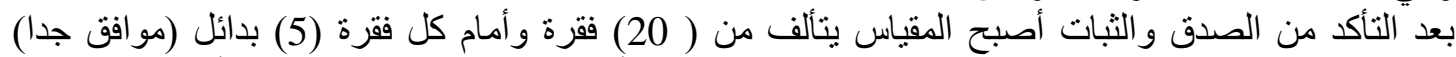

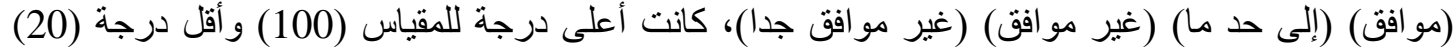

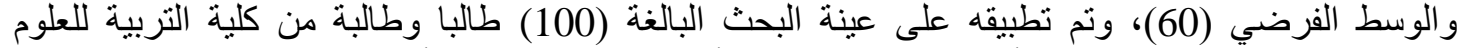
الإنسانية بجامعة ذب قار ولكافة الأقسام على مرحلتين (الأولىـ الثالثة) ولكافة الأقسام.

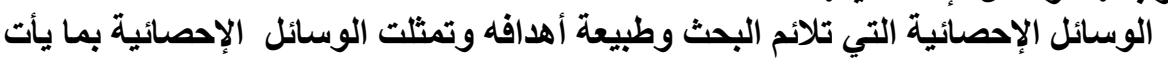

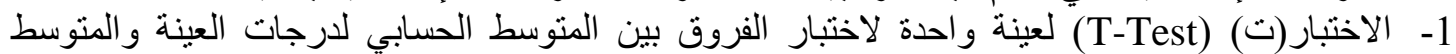

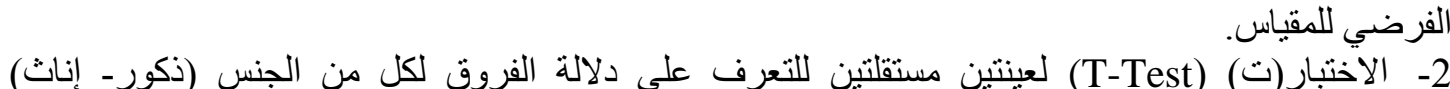

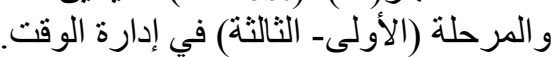

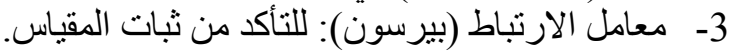

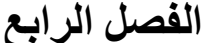

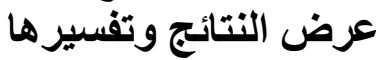

يتضمن هذا الفصل عرضا للنتائج التي توصل إليها البحث وتفسيرها في ضوء الإطار النظري ومقارنتها

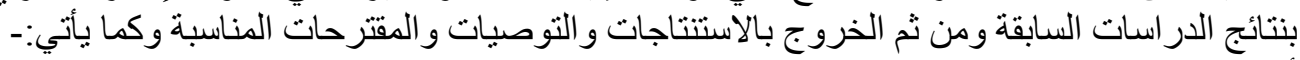

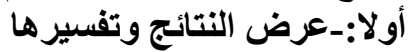

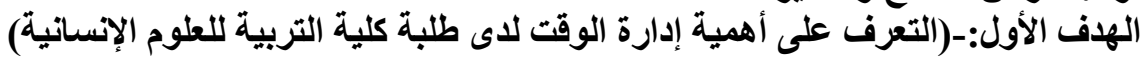

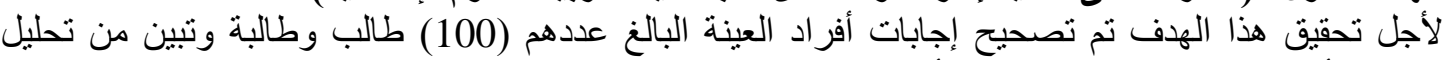

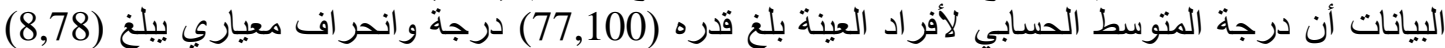

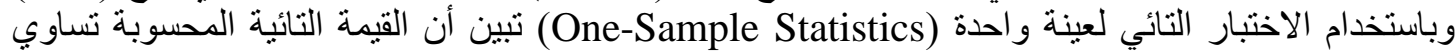

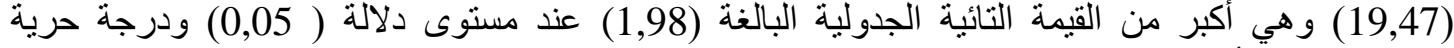

(99)و هذا يعني أن هنالك فرق دال إحصائيا كما موضح في الجدول (3):-

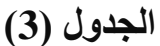

\begin{tabular}{|c|c|c|c|c|c|c|c|}
\hline \multirow[t]{2}{*}{ الدلالة } & \multirow[t]{2}{*}{ درجة الحرية } & \multirow{2}{*}{ مستوى } & \multicolumn{2}{|c|}{ القيمة التائية } & \multirow{2}{*}{ الانحياري اف } & \multirow{2}{*}{ الحسابي } & \multirow[t]{2}{*}{ العينة } \\
\hline & & & جدولية & محسوبة & & & \\
\hline دال & 99 & 0,05 & 1,98 & 19,472 & 8,87187 & 77,100 & 100 \\
\hline
\end{tabular}

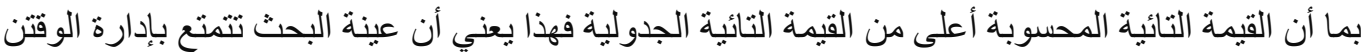

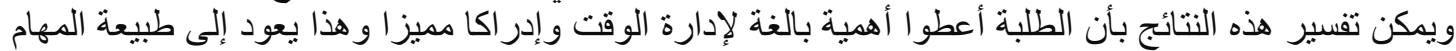

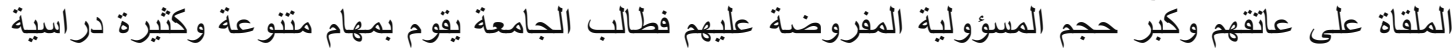

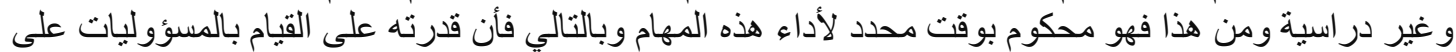
أكمل وجه تتطلب فيه إدارة وقت فعال قادرة على تتظيم أموره. 


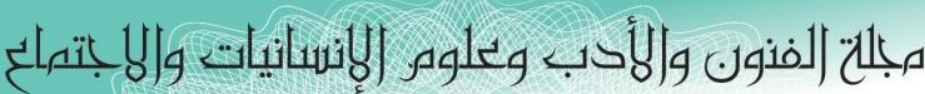

Journal of Arts, Literature, Humanities and Social Sciences

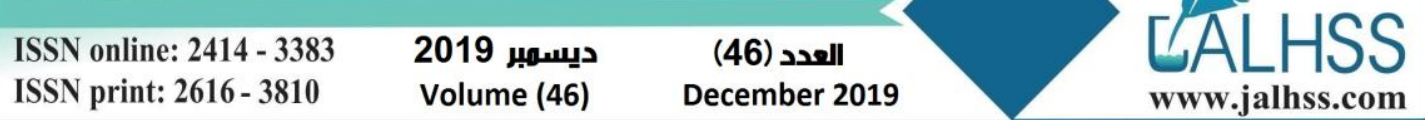

الهدف الثاني:- (التعرف على الفرق في أهمية إدارة الوقت لاى طلبة كلية التربية للعلوم الإنسانية تبعا لمتغير

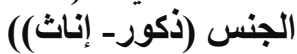

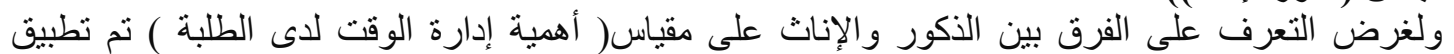

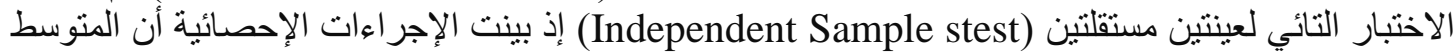

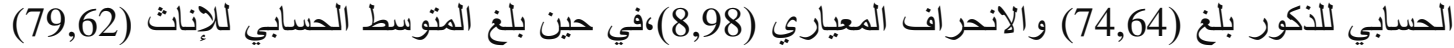

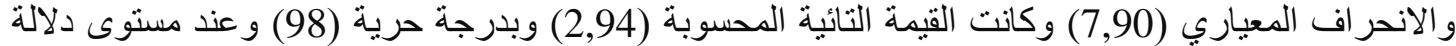

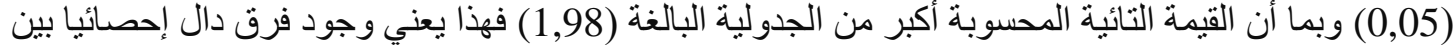
الذكور و الإناث لصالح الإناث كما موضح في الجدول(4):-

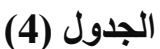

يمثل نتائج الإختبار التائي لعينتين مستقلتين لالالة الفرق في إدارة الوقت تبعا لمتفير الجنس

\begin{tabular}{|c|c|c|c|c|c|c|c|c|}
\hline \multirow{3}{*}{ الدلالة } & \multirow{3}{*}{ الحرية } & \multirow{3}{*}{ مستوى الدلالة } & \multirow{2}{*}{\multicolumn{2}{|c|}{ القيمة التائية }} & \multirow{3}{*}{ الانعرياري } & \multirow{3}{*}{ الحسابي } & \multirow{3}{*}{ العينة } & \multirow{3}{*}{ الجنس } \\
\hline & & & & & & & & \\
\hline & & & جدولية & محسوبة & & & & \\
\hline دال & 98 & 0,05 & 1,98 & 2,943 & 8,98 & 74,64 & 50 & ذكور \\
\hline & & & & & 7,90 & 79,62 & 50 & إناث \\
\hline
\end{tabular}

يمكن تفسير هذه النتيجة بأن الإناث أكثر تفرغا من الذكور مما يجعلهن أكثر إدارة للوقت وكثرة الأعباء الملقاة

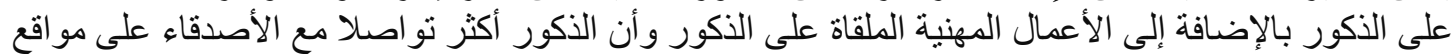

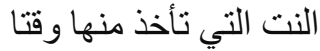
كثيرا والإناث أكثر اهتماما بإدارة أوقاتهن الدراسية و أكثر إحساسا بالمسؤولية تجاه الواجبات الأكاديمية من

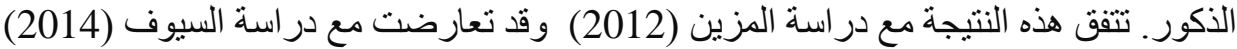

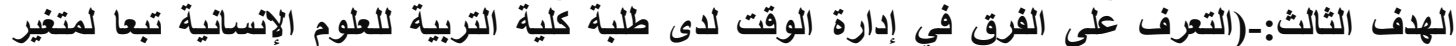
(المرحلة (أولى- ثالثة) (التيرف)

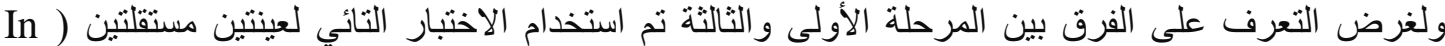
dependent Sample Stest)

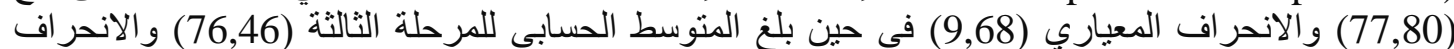

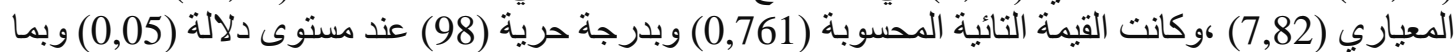

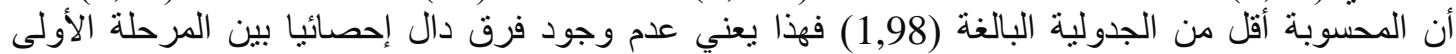

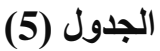
و الثالثة كما موضح في الجدول (5):-

يمثل نتائج الاختبار التائي لعينتين مستقلتين لالالة الفرق في إدارة الوقت تبعا لمتفير المرحلة (أولىـ ثالثة)

\begin{tabular}{|c|c|c|c|c|c|c|c|c|}
\hline & الدلالة & الحرية & الدستوى & القيمة التائية & الالنحر اف & الحسابي & العينة & المرحلة \\
\hline غير دال & 98 & 0,05 & 1,98 & 0,761 & 9,68 & 77,80 & 50 & أولى \\
\hline & & & & & 7,82 & 76,46 & 50 & ثالثة \\
\hline
\end{tabular}




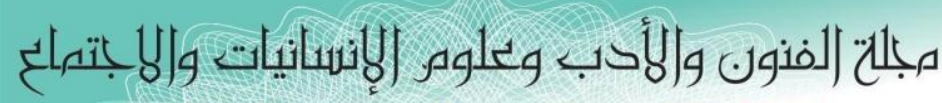

Journal of Arts, Literature, Humanities and Social Sciences

ISSN online: 2414 - 3383

ISSN print: 2616 - 3810

\section{9 ديسقبر}

Volume (46)

(46) (4) (العدد

December 2019

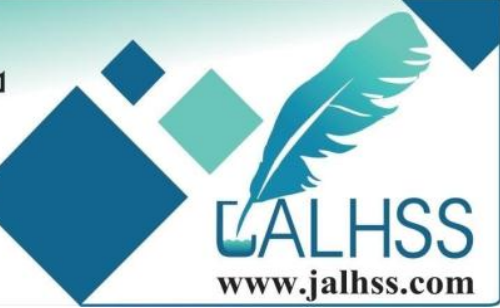

ويمكن تفسير هذه النتيجة بأن طلبة المرحلة الأولى لا يختلفون عن طلبة المرحلة الثالثة لأنهم ينتمون إلى البيئة

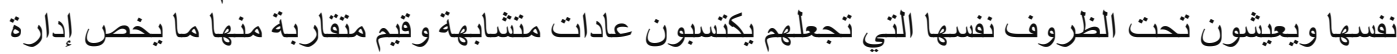

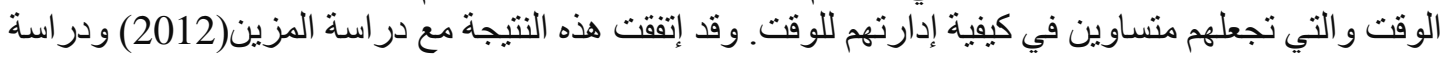
الزهر اني (2010).

| - الاستنتاجات:-

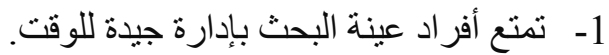

2- يوجد فرق ذات دلالة إحصائية عند مستوى دلالة (0,05) لدى طلبة كلية التربية للعلوم الإنسانية وفق متغير

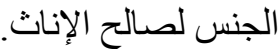

3- يوجد فرق ذات دلالة إحصائية عند مستوى دلالة (0,05) لدى طلبة كلية التربية للعلوم الإنسانية وفق متغير

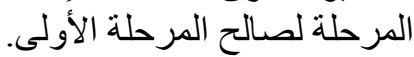

التوصيات:-

(1) ضرورة أن تطلع إدارة الجامعة بدور أفضل للعمل على زيادة أهمية إدارة الوقت لدى الطلبة عبر البرامج

الأكاديمية و التدريبية.

(2) إقامة ورش عمل في مجال إدارة الوقت من قبل إدارة الكلية لمساعدة الطلبة على كيفية إدارة وقتهم الدراسي.

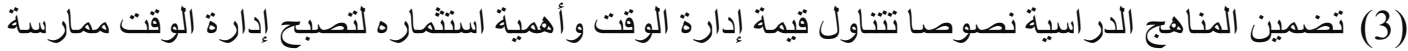

يتعايش معها الطلبة.

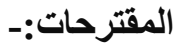

تقدم الباحثة عدد من المقترحات ومنها:-

(1) إجر اء در اسة مماتلة للار اسة الحالية على مر احل التعليم المختلفة غير الجامعة مثل طلبة المرحلة الإعدادية.

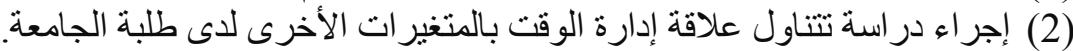

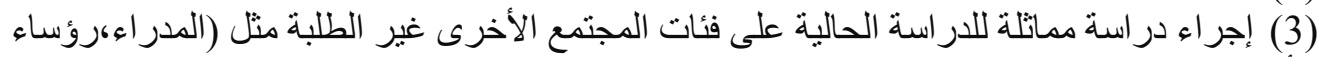

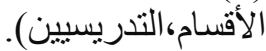

المصادر

القزآن الكريح.

1. الأسطل ، أميمة عبد الخالق عبد القادر.(2009). فاعلية إدارة الوقت وعلاقتها بالأنماط القيادية لدى ولئ

مديري المدارس الثانوية بمحافظات غزة من وجهة نظرة هم. رسالة ماجسنير غير الإنة منشورة،كلية

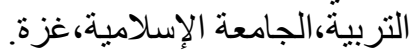

2.

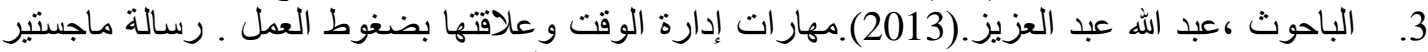

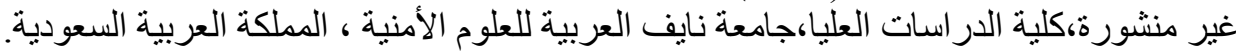

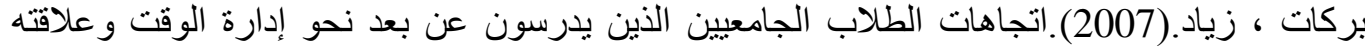

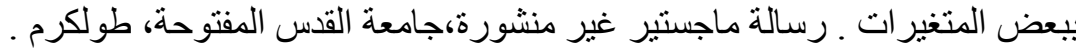

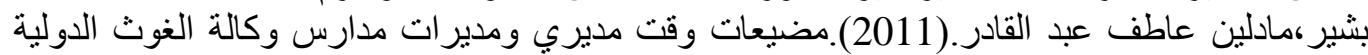

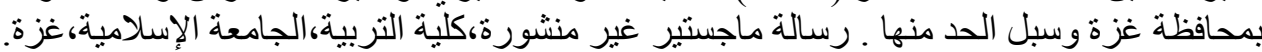
6.

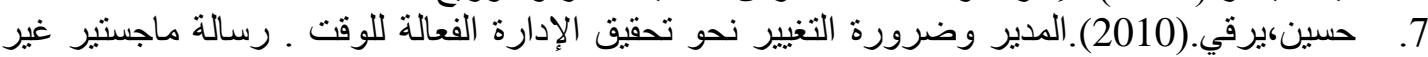

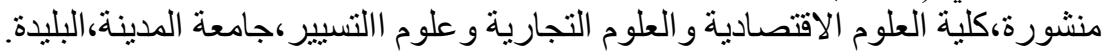

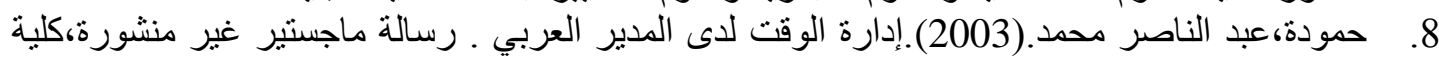
التجارة،جامعة اسيوط، القاهرة. 
مبلحت (لفنون والأدب وعلوه الإنسانيات والبانتهاع

Journal of Arts, Literature, Humanities and Social Sciences

ISSN online: 2414 - 3383

ديسمبر 2019

ISSN print: 2616 - 3810

العدد (46)

December 2019

9. الخطيب،عبير فوزي.(2009).إدارة الوقت وأثرها في مستوى أداء العاملين ـ جامعة الثرق الأوسط

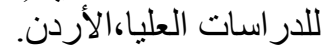

10. الرحيمي،سالم؛المارديني،توفيق.الإدئ. (2014).أثر إدارة الوقت في التحصيل الأكاديمي للطلبة.بجامعة أربد

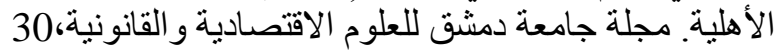

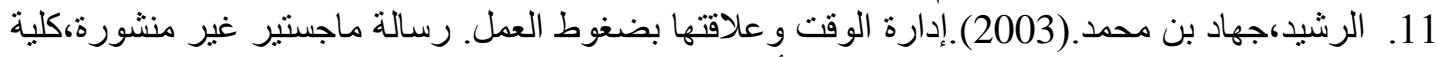

الدراسات العليا،جامعة نايف العربية للعلوم الأمنية، المملكة العربية العانية السعودية.

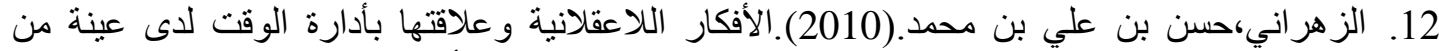

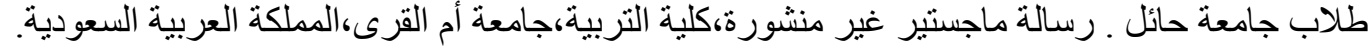

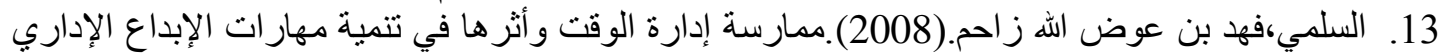

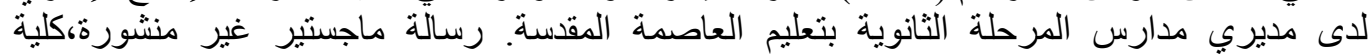
التربية،جامعة أم القرى، المملكة العربية السعودية.

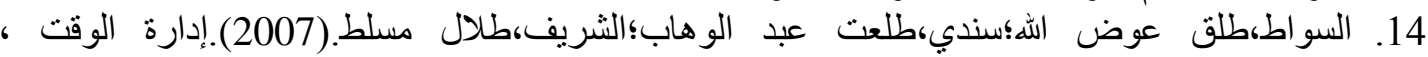

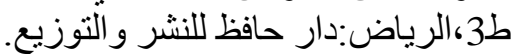

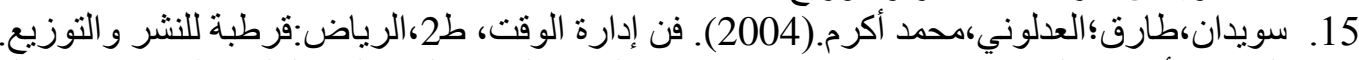

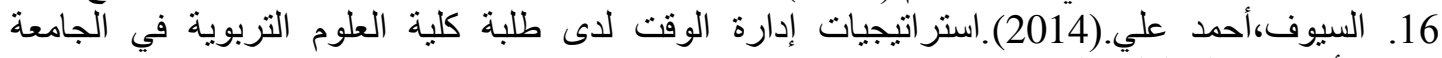
الأردنية.مجلة العلوم التربوية، 120 (2012). 17. شحادة،محمد أمين.(2012).إدارة الوقت بين الترانة التراث و المعاصرة، ط1،المملكة العربية السعودية: دار أبن الجوزي للنشر و التوزيع.

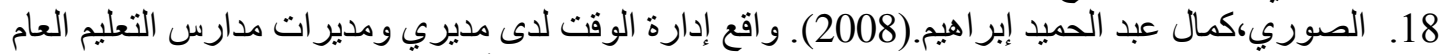

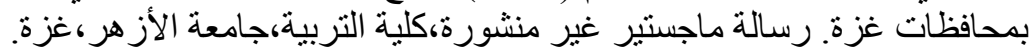

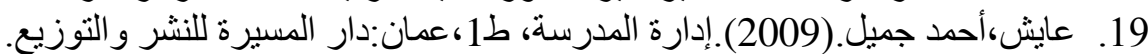

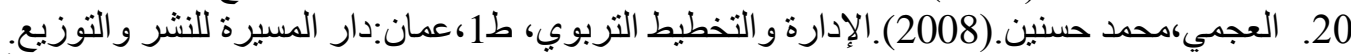

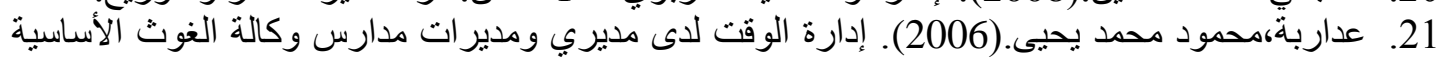

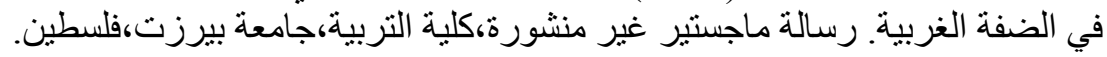

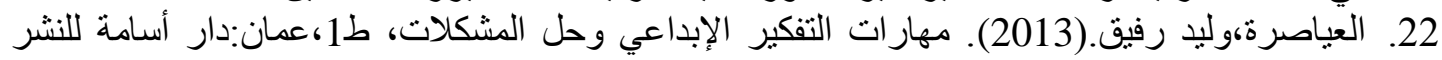

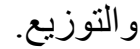
23. الغافري،فوزية بنت خلفان بن حميد.(2011). فاعلية برنامج إرشادي جمعي في تحسين مهارة تنظيم

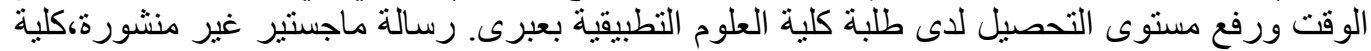
العلوم والآداب، جامعة نزوى العزى، عمان.

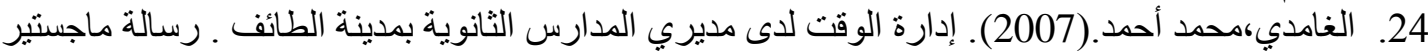

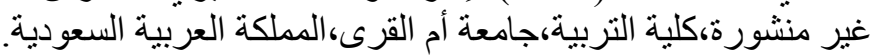

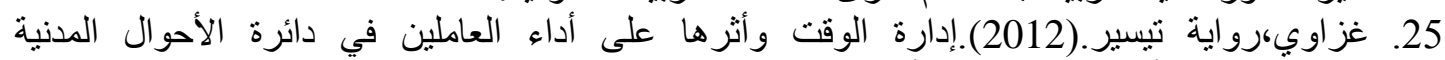

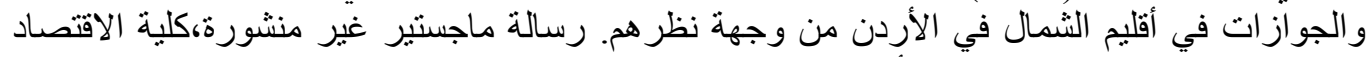

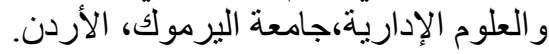

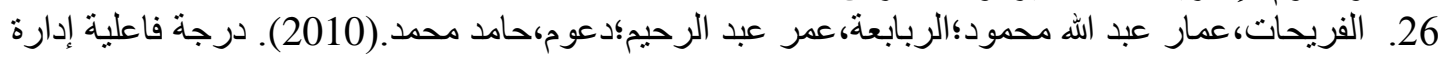

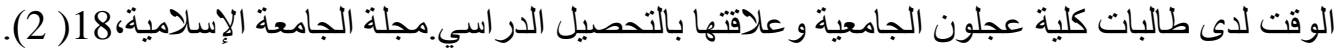

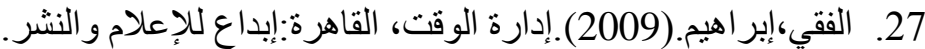

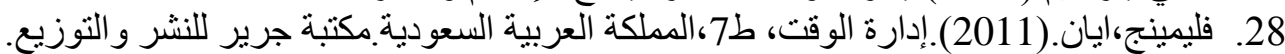

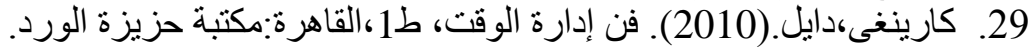

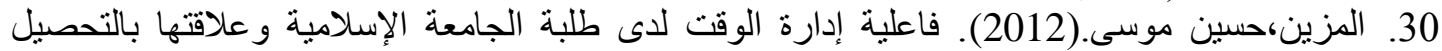

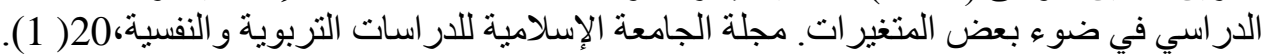

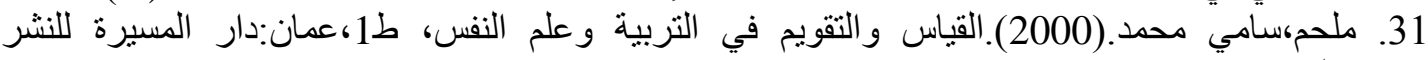
و التوزيع. 


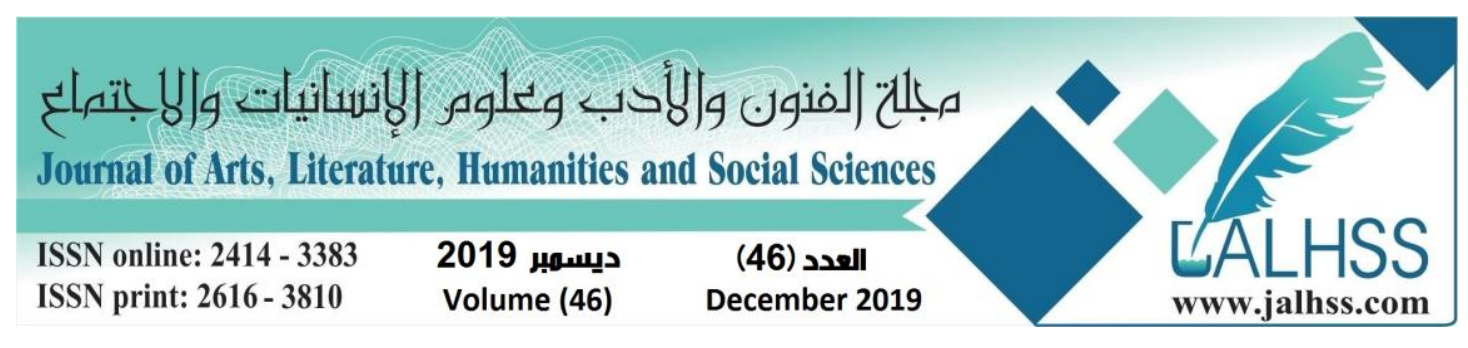

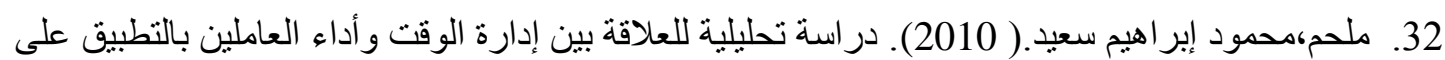

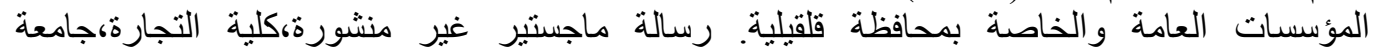

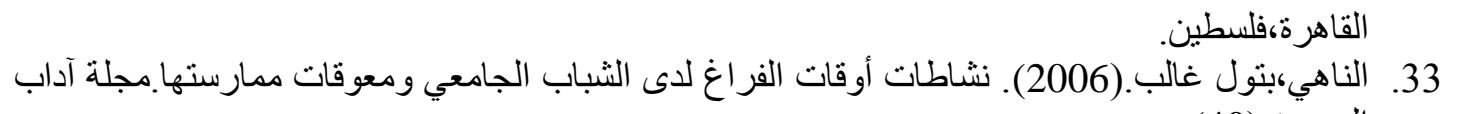

33. البصاهي،بونول غالب.(40).

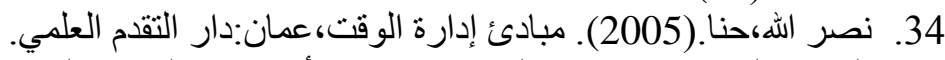

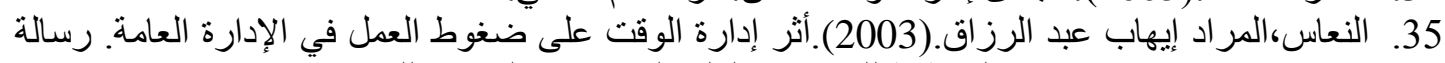

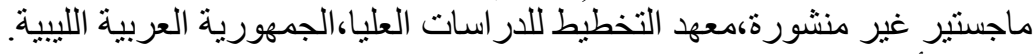

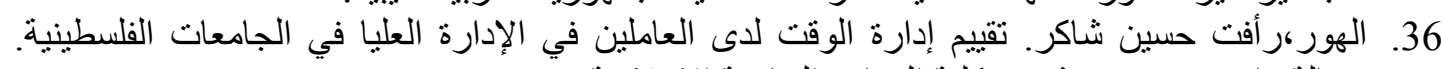

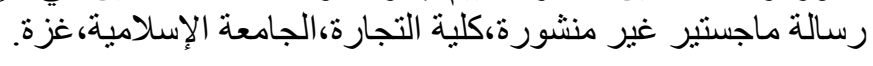

\section{References}

1. Al-Astal, Omaima Abdel-Khalek Abdel-Kader. (2009) The Effectiveness of Time Management and its Relationship with the Leadership Patterns of Secondary School Principals in Gaza Governorates From Their Perspectives. Unpublished Master Thesis, Faculty of Education, Islamic University, Gaza.

2. Al-Saif, Abdullah bin Mubarak (d.) Art of Time Management, Riyadh: Dar Taibah for Publishing and Distribution.

3. Researcher, Abdullah Abdul Aziz. (2013) time management skills and their relationship to work stress. Unpublished Master Thesis, College of Graduate Studies, Naif Arab University for Security Sciences, Saudi Arabia.

4. Barakat, Ziad (2007). Attitudes of university students studying distance to time management and its relationship to some variables. Unpublished Master Thesis, Al-Quds Open University, Tulkarm.

5. Bashir, Madeleine Atef Abdel-Kader. (2011). Unpublished Master Thesis, Faculty of Education, Islamic University, Gaza.

6. Beetle, Leicester. (1999). Time Management, Jordan: El - Ahlia for Publishing \& Distribution.

7. Hussein, Yargui. (2010) Director and the need for change towards achieving effective time management. Unpublished Master Thesis, Faculty of Economics, Business and Management Sciences, Medina University, Blida.

8. Hamouda, Abdel Nasser Mohamed (2003). Time Management with the Arab Director. Unpublished Master Thesis, Faculty of Commerce, Assiut University, Cairo.

9. Al-Khatib, Abeer Fawzi. (2009) Time management and its impact on the level of staff performance. Middle East University for Graduate Studies, Jordan.

10. Al-Rahimi, Salem; Al-Mardini, Tawfiq. (2014) Effect of Time Management on Students' Academic Achievement, Irbid National University. Damascus University Journal for Economic and Legal Sciences, 30. 


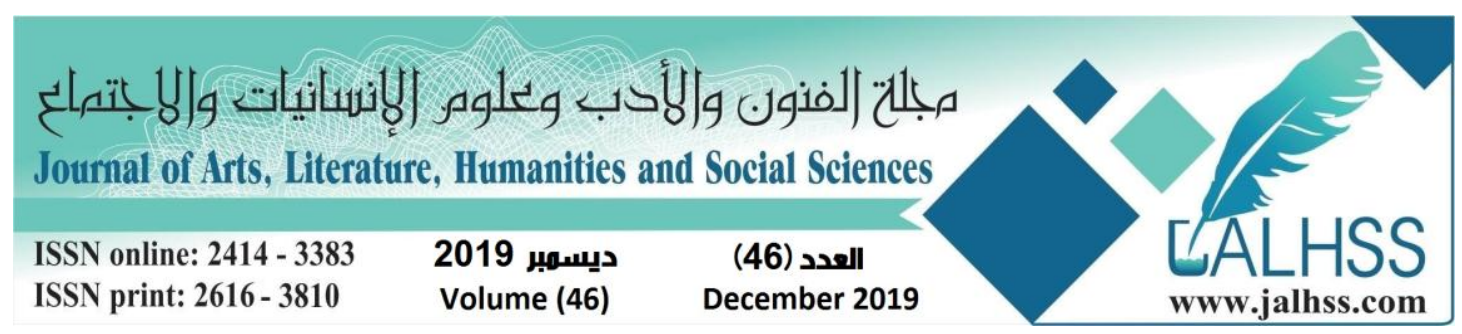

11. Al-Rasheed, Jihad Bin Mohammed (2003) Time Management and its Relationship with Work Stress. Unpublished Master Thesis, College of Graduate Studies, Naif Arab University for Security Sciences, Saudi Arabia.

12. Zahrani, Hassan bin Ali bin Mohammed (2010) irrational ideas and their relationship to time management among a sample of students of the University of Hail. Unpublished Master Thesis, College of Education, Umm Al-Qura University, Saudi Arabia.

13. Al-Salmi, Fahad Awadallah Zahem (2008) Practice of Time Management and its Effect on Developing Administrative Creativity Skills for Secondary School Principals in the Holy Capital Education. Unpublished Master Thesis, College of Education, Umm Al-Qura University, Saudi Arabia.

14. Al-Sawat, Talaq Awadallah; Cindy, Talaat Abdul Wahab; Al-Sharif, Talal Musallat (2007) Time Management, Riyadh: Hafez Publishing and Distribution House.

15. Suwaidan, Tariq; Al-Adlouni, Mohammad Akram. (2004) The Art of Time Management, 2nd Floor, Riyadh: Qurtuba for Publishing and Distribution.

16. Al-Seyouf, Ahmad Ali. ((2014) Time Management Strategies for Students of the Faculty of Educational Sciences at the University of Jordan. Journal of Educational Sciences, 41 (2).

17. Shehadeh, Mohammad Amin. (2012). Time Management between Heritage and Contemporary, Saudi Arabia: Ibn Al-Jawzi Publishing and Distribution House.

18. Al-Suri, Kamal Abdel-Hamid Ibrahim. (2008) The reality of time management among the principals and principals of public education schools in the governorates of Gaza. Unpublished Master Thesis, Faculty of Education, AlAzhar University, Gaza.

19. Ayesh, Ahmad Jamil. (2009) School Administration, Amman: Dar Al-Masirah for Publishing and Distribution.

20. Al-Ajmi, Mohammad Hassanein. (2008) Management and Educational Planning, 1st Floor, Amman: Dar Al-Masirah for Publishing and Distribution.

21. Adarbeh, Mahmoud Mohammed Yahya (2006) Time Management for Principals of UNRWA Schools in the West Bank. Unpublished Master Thesis, Faculty of Education, Birzeit University, Palestine.

22. Al-Ayasrah, Walid Rafiq. (2013) Skills of creative thinking and problem solving, 1st floor, Amman: Osama House for Publishing and Distribution.

23. Al-Ghafri, Fawzia bint Khalfan bin Humaid. (2011) The effectiveness of a collective counseling program in improving the skill of time management and raising the level of achievement among students of the College of Applied Sciences in Ibri.

24. Al-Ghamdi, Mohammed Ahmed (2007) Time Management for Secondary School Principals in Taif. Unpublished Master Thesis, College of Education, Umm Al-Qura University, Saudi Arabia.

25. Ghazzawi, Tayseer (2012) Time Management and its Impact on the Performance of Civil Status and Passport Workers in the Northern Region of 


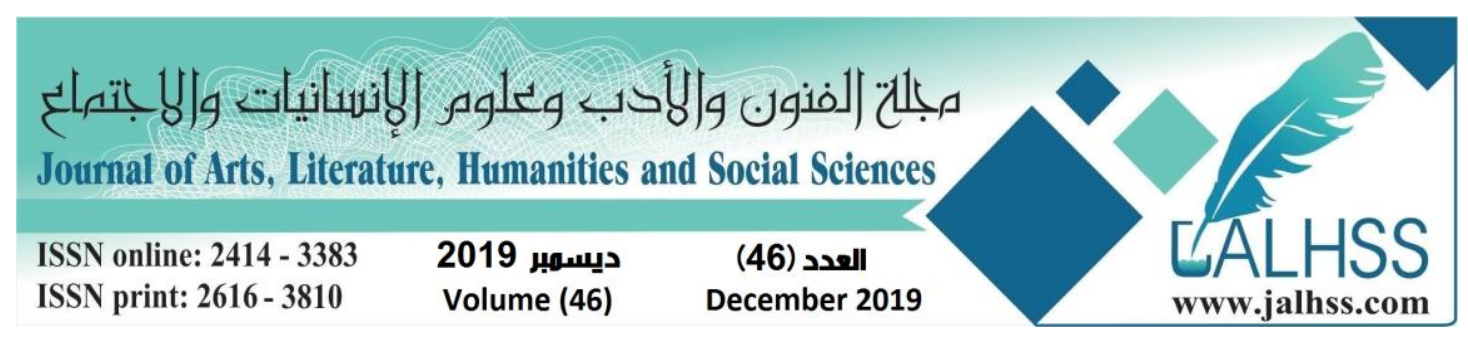

Jordan from their Perspectives. Unpublished Master Thesis, Faculty of Economics and Administrative Sciences, Yarmouk University, Jordan.

26. Al-Fraihat, Ammar Abdullah Mahmoud; Al-Rababa'a, Omar Abdel-Rahim; Daoum, Hamed Mohammed (2010). Degree of Effectiveness of Time Management among Ajloun University College Students and its Relation to Academic Achievement. Islamic University Journal, 18.

27. Al-Feki, Ibrahim (2009) Time Management, Cairo: Creativity for Media and Publishing.

28. Fleming, Ian. (2011) .Time Management, Saudi Arabia. Jarir Bookstore for Publishing and Distribution.

29. Caringy, Dale (2010) The Art of Time Management, 1st Floor, Cairo: Hazaiza El Ward Library.

30. Al-Muzayyen, Hussein Musa, (2012). The Effectiveness of Time Management among the Students of the Islamic University and its Relationship with Academic Achievement in the Light of Some Variables.

31. Melhem, Sami Mohammed (2000). Measurement and evaluation in education and psychology, Amman: Dar Al-Masirah for Publishing and Distribution.

32. Melhem, Mahmoud Ibrahim Said ((2010) an analytical study of the relationship between time management and the performance of workers applied to public and private institutions in Qalqilya Governorate. Unpublished Master Thesis, Faculty of Commerce, Cairo University, Palestine.

33. Al-Nahi, Batoul Ghalib. (2006) Leisure activities among university youth and obstacles to their practice.

34. Nasrallah, Hanna (2005) Principles of Time Management, Amman: Scientific Progress House.

35. Al Na'as, Ihab Abdul Razzaq, (2003) Effect of Time Management on Work Stress in Public Administration. Unpublished Master Thesis, Planning Institute for Graduate Studies, Libyan Arab Republic.

36. Hor, Raafat Hussein Shaker. Evaluating the time management of senior management in Palestinian universities. Unpublished Master Thesis, Faculty of Commerce, Islamic University, Gaza. 